\title{
Elastin-like Recombinamers: Deconstructing and Recapitulating the Functionality of Extracellular Matrix Proteins Using Recombinant Protein Polymers
}

\author{
Sergio Acosta, Luis Quintanilla-Sierra, Lubinda Mbundi, Virginia Reboto and \\ José Carlos Rodríguez-Cabello*
}

BIOFORGE (Group for Advanced Materials and Nanobiotechnology), CIBER-BBN, University of Valladolid, 47011 Valladolid, Spain

*roca@bioforge.uva.es

Keywords: elastin-like recombinamers, tropoelastin, elastin, biofabrication, tissue engineering

\begin{abstract}
In the development of tissue engineering strategies to replace, remodel, regenerate or support damaged tissue, the development of bio-inspired biomaterials that recapitulate the physico-chemical characteristics of the extra-cellular matrix has received increased attention. Given the compositional heterogeneity and tissue-to-tissue variation of the extra-cellular matrix, the design, choice of polymer, crosslinking and nature of the resulting biomaterials is normally depended on intended application. Generally, these biomaterials are usually made of degradable or non-degradable biomaterials that can be used as cell or drug carriers. In recent years, efforts to endow reciprocal biomaterial-cell interaction properties in scaffolds has inspired controlled synthesis, derivatization and functionalization of the polymers used. In this regard, elastin-like recombinant proteins have generated interest and continue to be developed further owing to their modular design at a molecular level. In this review, we provide a summary of key extracellular
\end{abstract}


matrix features relevant to biomaterials design and discuss current approaches in the development of extra-cellular matrix-inspired elastin-like recombinant protein based biomaterials. 


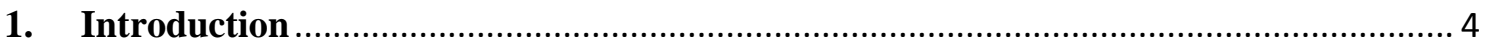

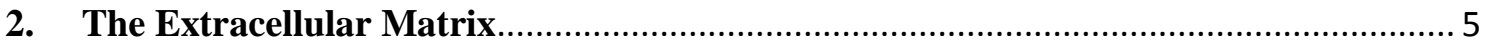

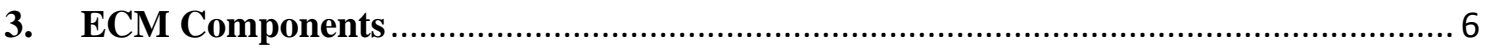

3.1. Structure and Function of Proteoglycans …….................................................... 7

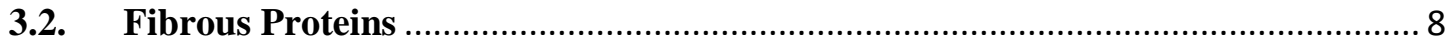

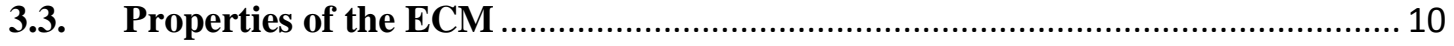

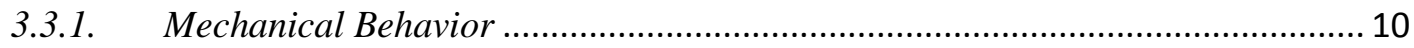

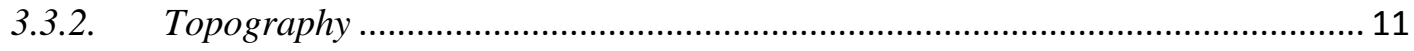

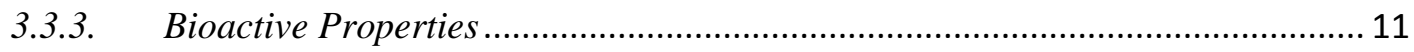

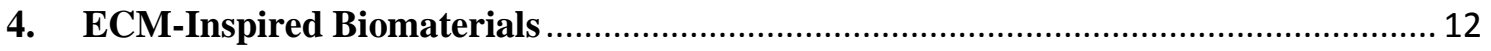

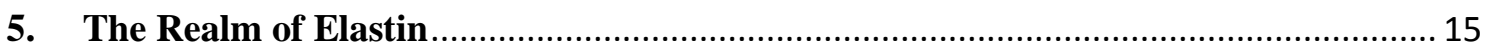

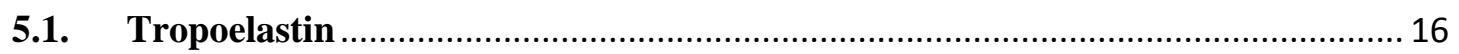

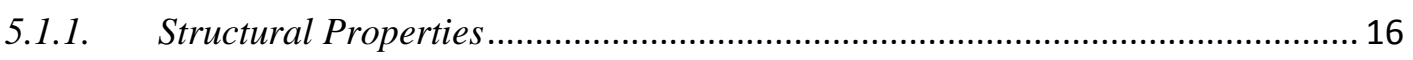

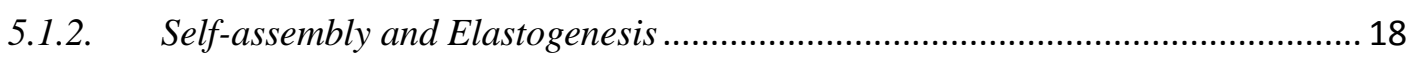

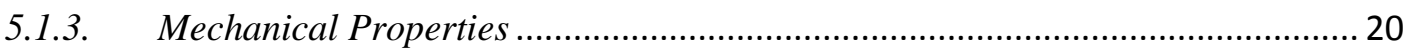

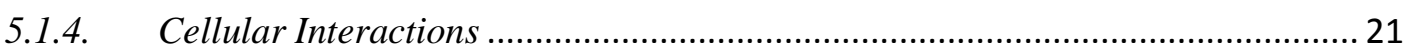

5.2. Relationship between Intrinsic Disorder and Elasticity ..................................... 21

5.3. Tissue Repair and Regeneration based on Engineered Tropoelastin................... 24

5.3.1. Recombinant Tropoelastin for Cardiovascular Applications............................... 25

5.3.2. Recombinant Tropoelastin for Dermal Applications ........................................ 26

5.3.3. Recombinant Tropoelastin for other TERM Applications ................................... 28

6. Emergence of New Elastin-based Biomaterials: Elastin-like Recombinamers............. 30

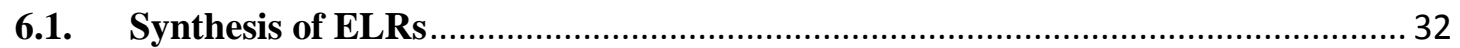

6.2. ELR-based 3D Scaffolds for TERM Applications.................................................. 34

6.2.1. Physically Crosslinked Elastin-like Scaffolds ................................................... 34

6.2.2. Chemically Crosslinked Elastin-like Scaffolds................................................. 37

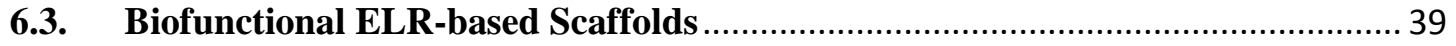

6.4. Architecture and Stiffness Control ............................................................... 43

6.5. Cell-Stimulated Remodeling of ELR-based Scaffolds …..................................... 45

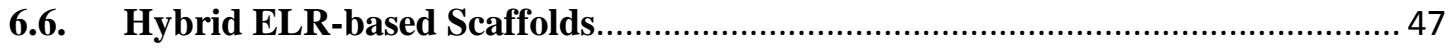

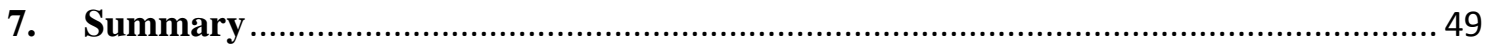




\section{Introduction}

Tissue integrity is maintained by complex reciprocal interactions between the cells and the extracellular matrix (ECM) within which they are compartmentalized. ${ }^{[1,2]}$ While the human body has the ability to regenerate and heal small tissue defects, severe and large insult to tissue resulting from injury, disease or congenital defects are more difficult and present significant medical and socioeconomic challenges. ${ }^{[3,4]}$ To address this, tissue engineering and regenerative medicine (TERM) strategies, which include cell-based therapies, biomaterials and a combination of both, with the aim to repair, replace, remodel, regenerate or support damaged tissue have seen significant advancements and continue to be developed further. In this regard, the development of biomaterials that recapitulate the morphological, mechanical and biochemical properties of the ECM has received increased advocacy. ${ }^{[5,6]}$ Hereof, it is well accepted that an ideal ECMmimicking scaffold should not only be able to provide a dynamic multifunctional network able to transduce mechanical and biochemical signals that regulate cellular activities but should also be dynamic and get remodelled along with the changing cellular environment. ${ }^{[7]}$

Given the heterogeneity of the ECM and variation across and within different tissues, the choice of the polymers used in scaffold development, the nature of the scaffold (e.g. crosslinking type, degradation rate, functionalization etc.) is dependent on the intended application and target tissue. In this regard, natural polymers are widely used in the fabrication of ECM-inspired scaffolds for TERM applications because they offer a wide range of physicochemical and mechanical properties combined with an inherent biological recognition. ${ }^{[8,9]}$ However, since natural polymers have a pre-determined structure and the degree to which they can be derivatized and functionalized to endow desired properties is limited, genetically engineering polymers have received increased 
advocacy. This is because recombinant technologies allow for the controlled and modular synthesis of the polymers tailored for the desired application at a molecular level. Indeed, genetically engineered biomaterials based on structural proteins (e.g. collagen, ${ }^{[10]}$ laminin, ${ }^{[11]}$ resilin $^{[12]}$ or elastin ${ }^{[13]}$ ) are promising candidates in the development of biomaterials for TERM. Their recombinant synthesis allows the production of tailored scaffolds with precise chemical composition and tunable bioactivities. In addition, the great variety of functional protein building blocks, including structural, self-assembling or bioactive motifs, opens a wide range of possibilities in the production and manufacturing of protein-based ECM-inspired biomaterials. Additionally, recent advances in the expression systems and recombinant DNA techniques demonstrate the feasibility for large scale production. ${ }^{[14]}$

In this review, we provide a summary of key ECM features explored in biomaterials design. We further highlight the physico-chemical features of elastin and elastin like recombinamers and discuss current approaches in the development of ECM-inspired elastin-like recombinant biomaterials.

\section{The Extracellular Matrix}

The extracellular matrix (ECM) is ubiquitous and consists of a complex mixture of interconnected cell-secreted molecules arranged to provide physical scaffolding for cells and tissues, and to initiate physicochemical cues vital for normal tissue morphogenesis, differentiation, homeostasis and healing. ${ }^{[15,16]}$ Fundamentally, human ECM is composed of water, proteins and polysaccharides whose varying ratios within and across different tissues reflect local functional requirements. ${ }^{[16]}$ Indeed, this marked variation in ECM composition and topology across and within different tissues is generated during tissue development and or regeneration (i.e. during wound healing) through a dynamic, reciprocal and reiterative biochemical and biophysical dialogue between the various 
cells and the evolving cellular microenvironment. ${ }^{[15]}$ The physical, topological, and biochemical composition of the ECM creates a variety of distinct tissue-specific environments that recruit and modulate the activities of different cell types as per requirement. ${ }^{[15,17]}$

The complex ECM architecture is represented schematically in Figure 1.

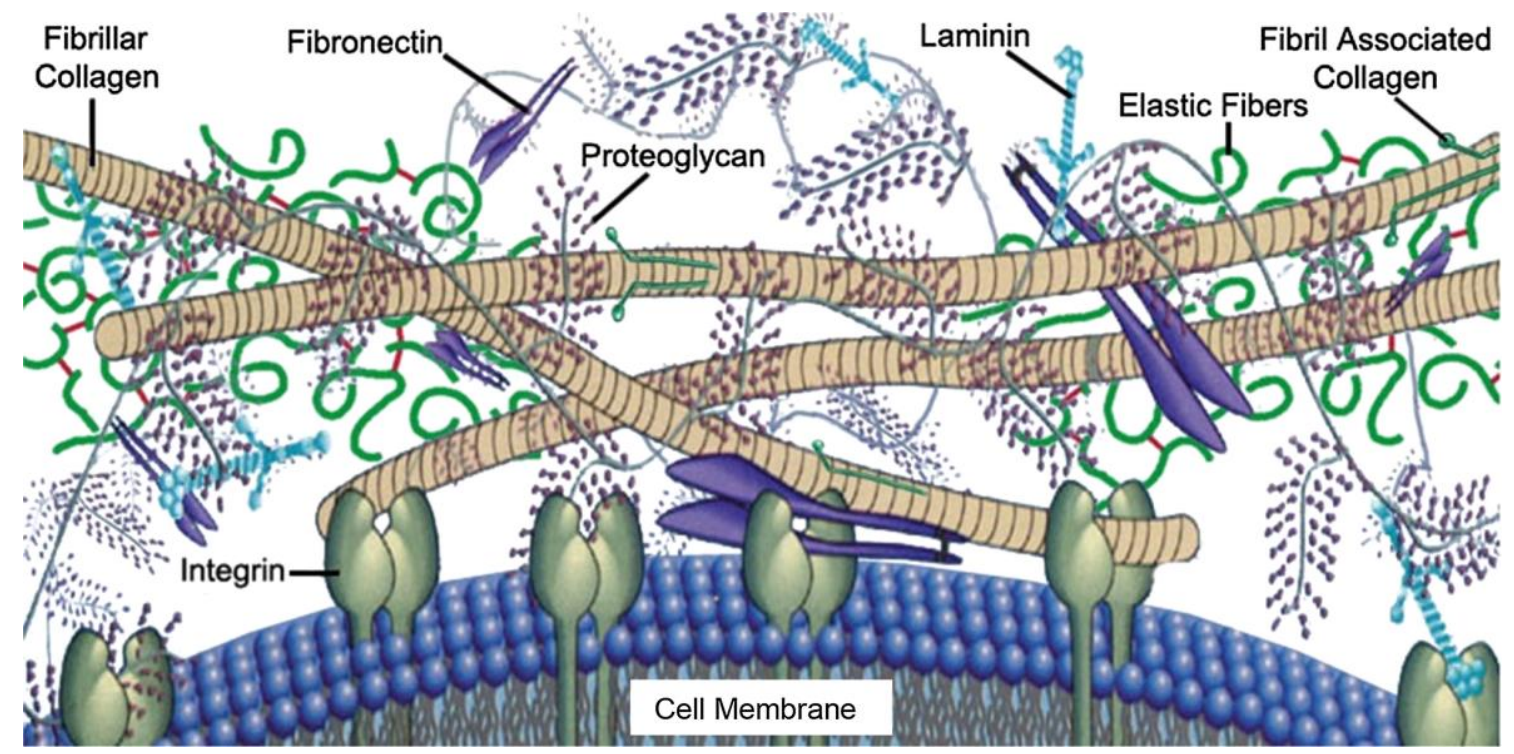

Figure 1. Scheme of the general ECM space showing some primary ECM components and the interactions between these components and cells. Reproduced with permission. ${ }^{[18]}$ Copyright 2016, Elsevier.

\section{ECM Components}

Structurally, the ECM is mainly composed of two major classes of biomolecules: glycosaminoglycans (GAGs) which are, with the exception of a soluble ones (e.g. hyaluronic acid), mostly covalently linked to proteins forming proteoglycans, and fibrous proteins, which include collagens, elastin, laminins and fibronectins. ${ }^{[19]}$ Through the inter-cellular and cell-ECM interactions, cells produce, organize and determine the type and ratio of both structural and non-structural proteins and molecules following biochemical and mechanical stimuli. 


\subsection{Structure and Function of Proteoglycans}

Proteoglycans (PGs) consist of highly anionic GAG chains covalently linked to a particular protein core, with the exception of hyaluronan (or hyaluronic acid) as it lacks a protein core. ${ }^{[20]}$ GAGs are highly varied in size, structure and chemistry, which results in a great diversity within a given tissue. Indeed, GAGs form unbranched polysaccharide chains composed of repeating disaccharide units [e.g. sulfated $\mathrm{N}$ aceltylglucosamine or $\mathrm{N}$-acetylgalactosamine, D-glucuronic or L-iduronic acid and galactose ( $-4 \mathrm{~N}$ - acetylglucosamine- $\beta 1,3$-galactose- $\beta 1)]$, which can be classed as either sulfated (e.g. chondroitin sulfate, heparan sulfate and keratan sulfate) or non-sulfated (e.g. hyaluronic acid) GAGs. ${ }^{[20]}$ Owing to their anionic nature, proteoglycans are extremely hydrophilic, and their highly extended conformation of tethered GAGs amplifies their water-holding capacity. This enables the tissues within which they are complexed to withstand high compressive forces (i.e. cartilage and skin). ${ }^{[20,21]}$ Generally, these molecules can be classified according to their core proteins, localization, GAG composition and size (large or small proteoglycans), with the latter being the most common classification. Large proteoglycans (e.g. major proteoglycan of cartilage, aggrecan and the fibroblast-derived large proteoglycan, versican) have numerous highly sulfated GAG sidechains with high water-holding capacity and tend to be abundant in ECMs ideally suited to withstanding high compressive forces (i.e. cartilage, tendon and skin). ${ }^{[22]}$ In contrast, small proteoglycans (e.g. decorin, biglycan, fibromodulin and lumican) have only one or two GAG side chains and are closely associated with the collagen fibrils with a wide tissue distribution playing both structural and regulatory roles (e.g. cell growth, adhesion, migration, differentiation, angiogenesis). ${ }^{[23]}$ Indeed, variety of functions that reflect their unique buffering, 
hydration, binding and force-resistance properties. Several genetic and acquired diseases have also been linked to mutations in proteoglycans genes. ${ }^{[15,21]}$

\subsection{Fibrous Proteins}

Of all the fibrous proteins, collagens are the most abundant and main structural component of the interstitial ECM. ${ }^{[16,24]}$ Different cells secrete collagen, with fibroblasts secreting the most, and arrange the majority of it into triple-stranded helixes. Some of these helixes, depending on collagen type, are further arranged into supramolecular complexes such fibrils, sheets and cables that provide tensile strength, regulate cell adhesion, support chemotaxis and migration, and direct tissue development and or remodeling. ${ }^{[15,25]}$ There are currently at least 27 types of collagens (collagen I - XXIX) known in vertebrates, with 42 distinct polypeptide chains (alpha chains) and over 20 additional proteins with collagen-like domains. ${ }^{[26]}$ While collagen fibrils are generally a mixture of different collagen types at varying ratios, one type normally predominates (i.e. collagen I in skin and collagen II in cartilage). ${ }^{[15,24,26]}$

Generally, the triple helical domains of collagen form as a result of glycine (G) being used in every third residue (i.e., repeating peptide triplets of GXY, where $\mathrm{X}$ is often proline, and Y is frequently hydroxyproline). ${ }^{[24]}$ In each $\alpha$ chain, triple helical regions (termed Col domains), are flanked by non-collagenous (non-GXY) regions, which often contain recognizable peptide modules found in other matrix molecules. ${ }^{[24]}$ This molecular arrangement of collagen allows for the attachment of other structural and non-structural (e.g. GAGs discussed above) molecules to impart unique biomechanical and biochemical cues on cells and tissues.

One major structural protein that collagen associates with and provides complementary function to collagen is elastin, mainly as elastic fibers, which consist of tropoelastin and 
microfibrils. ${ }^{[27]}$ Whereas collagen provides tissue ECM with strength and the ability to withstand high pressure, elastin is responsible for reversible extensibility (recoil properties) of tissue and is particularly abundant in tissues that undergo repeated stretching (e.g. ligaments, lungs and blood vessels). ${ }^{[28]}$ Crucially, elastin stretching is limited by the tight association with collagen fibrils. ${ }^{[27]}$ The complex assembly of elastic fibers has been reviewed by others elsewhere. ${ }^{[27,29]}$ Briefly, elastin makes up the bulk of elastic fibers and it results from the assembly of and crosslinking of tropoelastin, its precursor. ${ }^{[29]}$ Secreted tropoelastin molecules assemble into fibers that are enzymatically crosslinked to one another through their lysine residues by the activities of the lysyl oxidase (LOX) enzyme family (e.g. LOX and LOXL). ${ }^{[30]}$ Elastin fibers are covered by glycoprotein microfibrils, mainly fibrillins along with other molecules such as fibulins, EMILIN-1 and microfibril associated glycoprotein (MAGPs) which are also essential for the integrity of the elastin fiber. ${ }^{[27,29]}$

Since elastin has a half-life equivalent to human lifespan (about 74 years) ${ }^{[31]}$ and the complexity of the formation of elastic fibers, which involves elaborate spatial and temporal regulation of all the involved proteins, recapitulation of elastic fibers in healing and or regenerating of adult tissues remains a challenge. ${ }^{[29]}$ As such, the incorporation of the elastin-like proteins in the design of ECM biomaterials should be considered to mitigate this shortfall, which affects cellular processes such as adhesion, migration, proliferation and differentiation.

Another important fibrous protein in the ECM, fibronectin, is mainly involved in directing the organization of the interstitial ECM as well as mediating cell attachment and function. Indeed, fibronectin is known to be susceptible to being stretched several times over its resting length by cellular traction forces. ${ }^{[32]}$ This cell-force-dependent unfolding and folding enables the exposure (or deactivation) of cryptic integrin-binding 
sites within the molecule that result in pleiotropic mechano-regulatory effects on cellular behavior. ${ }^{[32]}$

These structural molecules, their compositional and chemical makeup as well as nature of inter-molecular and cellular interactions influence local ECM $\mathrm{pH}$, the type and conformation of some of the secreted (soluble and non-soluble) molecules such as growth factors, cytokines, chemokines and proteases. ${ }^{[15]}$ These molecules present in the ECM are vital in the control of cellular responses and matrix remodeling.

\subsection{Properties of the ECM}

In order to mimic the features and properties of the ECM, various physiological ECM characteristics, including mechanical, topographical and biological properties, must be considered. $^{[33]}$

\subsubsection{Mechanical Behavior}

All tissues have distinct intrinsic mechanical properties, which are important for function and structure. ${ }^{[34]}$ Several non-invasive imaging techniques, such as ultrasound, optical coherence tomography, and magnetic resonance elastography, have been used for to measure tissue stiffness in vivo. ${ }^{[35]}$ However, a range of values can be found in the literature depending on the technique used, measurement scale and activity status of the tissue.

In vivo measurements have provided a range of values for the Young modulus, ranging from $10 \mathrm{kPa}$ for parenchymal tissue to $20 \mathrm{kPa}$ for muscle and $50 \mathrm{kPa}$ for connective tissue. ${ }^{[35]}$ Whereas mechanical characterization of explanted tissues provide values, ranging from $4 \mathrm{kPa}$ for parenchymal tissue to $12 \mathrm{kPa}$ for muscle and $60-100 \mathrm{kPa}$ for connective tissue. ${ }^{[36]}$ Quantitative changes in these mechanical properties have been 
used as an indication of disease progression in certain tissues or organs, for example the liver. $^{[37]}$

\subsubsection{Topography}

The main topographical characteristics of the ECM include fiber diameter, pore size, and feature elevation. ${ }^{[33,38]}$ As a fingerprint, each tissue shows a distinct microenvironment to cells inside it. For example, while dermal ECM fibers have a radius of around 30-60 $\mathrm{nm}$ that increases with depth, ${ }^{[39]}$ bone collagen fibers have a radius of about $40-50 \mathrm{~nm}$, including carbonate apatite regions. ${ }^{[40]}$ Moreover, some ECM environments are chaotic whereas others, such as the myocardium and tendons, are clearly organized, showing directionality and alignment with the cell layer. ${ }^{[41,42]}$ Thus, the nanotopography of each specific tissue requires a distinct biomaterial design to emulate it.

\subsubsection{Bioactive Properties}

Cells are involved in dynamic interactions with other cells and the matrix. Indeed, multivalent matrix-cell communication takes place via different cell receptors (integrin and non-integrin membrane receptors). Although the initial attraction is mediated by various low-affinity and hydrophobic interactions, cells need to establish focal adhesions with the ECM. ${ }^{[43]}$ These adhesions to bioactive cues present in the ECM enable dynamic communication by sending signals across the cell membrane, through the cytoskeleton, to soluble molecules in the cytoplasm and into the cell nucleus. As such, nanoscale control of these contacts results in the distribution of focal adhesion, adhesion sites and cytoskeletal arrangements. ${ }^{[44,45]}$ Even the function of a cell is affected by the interactions between it and the binding domains in its microenvironment. For instance, the bundles present in collagen fibers interact with a periodicity ranging from 
63 to $72 \mathrm{~nm}$ depending on the kind of tissue, and are partly responsible for the nanoscale topography. ${ }^{[46]}$

\section{ECM-Inspired Biomaterials}

The physical, mechanical and biochemical properties of the ECM are not only important for structural integrity but are of significant physiological relevance. Indeed, cells are able of sense ECM rigidity through integrin-mediated interactions with the matrix. The physicochemical properties of the matrix are then interpreted to affect motility, proliferation, differentiation, and apoptosis. Given the dynamic and reciprocal nature of the cell-ECM interaction, ECM may also get remodeled in the process. As such, understanding the precise composition of different tissues and their structure-function relationship is important and should be considered in the design of biomaterials for biomedical applications. $^{[16]}$

Considering natural ECM heterogeneity and its importance to many fundamental cellular process, numerous tissue culture techniques, in vivo studies and biomaterials have been developed in regenerative medicine to understand the interplay between ECM and cells so as to elucidate on, and harness these qualities for biomedical applications. ${ }^{[15,47]}$ In this regard, researchers using in vitro monolayer cultures of human cells have relied on coating tissue culture dishes (mostly plastic or glass) with different purified ECM-derived molecules so as to understand cell-ECM interactions. ${ }^{[48,49]}$ To address the absence of the multidimensional $3 \mathrm{D}$ environment physico-chemical cues, purified preparations or a mixture of ECM proteins (e.g. collagen, fibrinogen, elastin and silk) have been formulated into 3D scaffolds with promising results both in vitro and in vivo for different applications. ${ }^{[50]}$ However, since isolated polymers lack the compositional and physicochemical complexity of 
natural ECM, others have turned to studying and using natural ECM protein mixtures. In this regard, ECM protein mixture generated from Engelbreth-Holm-Swarm mouse carcinoma cell (Matrigel ${ }^{\mathrm{TM}}$ ), decellularized scaffolds and pastes (xenogeneic and human) as well as mixtures of collagen I, fibronectin and other ECM peptides have gained popularity as materials of choice in both in vitro and in vivo studies with some finding use in clinical applications. ${ }^{[50,51]}$ Indeed, researchers have generated denuded ECM scaffold from various tissues that, when combined with cargo stem cells, can reconstitute normal tissues with reasonable fidelity. ${ }^{[3,52]}$ Indeed, ECMs isolated from various tissues, which include, among others, skin, ${ }^{[53]}$ liver, ${ }^{[54]}$ small intestine, ${ }^{[55]}$ cartilage, ${ }^{[56]}$ and breast,${ }^{[57]}$ have been used for different studies and clinical application such as skin grafts, bone repair or to study tumor progression. ${ }^{[15,58,59]}$ Although these purified ECMs are useful and provide detailed testimonial of the cell-ECM cross-talk compared to that afforded by isolated and purified protein-scaffolds, their use is limited due to the need for well-defined bespoke microenvironments in tissue regeneration with limited or no animal byproducts or contaminants. Moreover, these strategies do not faithfully recapitulate natural ECM and the degree to which their structure and composition can be tailored to control remodeling through the reciprocal interaction with cells and the changing microenvironment is unclear. ${ }^{[15,50]}$ One of the main challenges is that these polymers and ECM protein mixture preparations (cell derived or decellularized tissues) are not only altered by the preparation process, but also have predetermined and rudimental protein structure, chemistry and composition, that only allows for limited degree of derivatization and functionalization with limited fidelity to native ECM. In addition, purified proteins and ECM preparations from animals and other natural sources have characteristic significant batch to batch variation, which makes experimental reproducibility a challenge and clinical efficacy unclear. ${ }^{[15]}$ 
To endow particular biophysical and biochemical properties that can elicit diverse but specific cellular activities, it is necessary to chemically and physically defined the ECMs that can be reliably reproduced. In this regard, synthetic matrices have been developed that feature defined and tunable compositions, organization, mechanics and ECM remodeling capabilities and are extensively reviewed by others. ${ }^{[60-66]}$ Although these matrices can be covalently modified with ECM ligands, endowed with enzymelabile degradation molecules (i.e. collagenase-degradable peptides) and growth factors, they do not mimic the organizational features of native structural proteins and their rigid structures after crosslinking often impede cell migration. ${ }^{[15]}$

\subsection{Recombinant Proteins}

By contrast, peptide-based hydrogels that can assemble into secondary structures and recapitulate structures such as the collagen triple helix, and readily support cell growth and viability, and direct multicellular morphogenesis offer both the benefits of natural protein chemistry and are amenable to modification by covalent binding of native proteins (including matrix metalloproteinase (MMP)-degradable ECM peptides). In line with this, the ability of to produce proteins in a controlled and modular manner at a molecular level is gaining popularity. In this approach, the protein of interest is genetically encoded and synthesized in a heterologous host (e.g. eukaryote cell or bacteria), which affords complete control on the amino acid sequence and molecular weight of the resulting protein. This is not easily achieved in peptide synthesis, especially for peptides with many amino acids (i.e. >20 amino acids), and in the derivatization of natural proteins. Common structural proteins on which recombinant

proteins have been modeled include silk, resilin, collagen and elastin. ${ }^{[12,67-70]}$ Elastinlike polypeptides (ELPs), the main subject of this review, are composed of a conserved 
pentapeptide repeat units with the classic form poly(Valine-Proline-Glycine-ValineGlycine). ${ }^{[67,71]}$ The conserved peptide sequence found in mammalian elastin has been extensively studied to determine its usefulness for specific biomedical applications (further discussed in section 6) and several recombinant ELPs have been developed for biomedical applications, including the production ECM-inspired biomaterials.

\section{The Realm of Elastin}

Elastin is a major component of ECM elastic fibers, where it endows elastic recoil and resistance properties as well as regulation of a range of cellular activities (i.e. adhesion, migration, proliferation and differentiation) within the ECM, particularly in tissues such as skin, cardiovascular system, lung and ligaments. ${ }^{[72,73]}$ These inherent qualities of elastin and the fact that it is closely linked to and provides complementary functions with collagen in the ECM makes it a desirable inclusion to adult wound healing and tissue regeneration. ${ }^{[74]}$ However, although elastin is highly durable, the metabolic replacement rate of elastin is very slow. ${ }^{[31]}$ This is attributed to the molecular complexity, size and the multiple macromolecules involved in fiber assembly, which places elastic fibers among the most difficult matrix structures to repair. Indeed, it is well established that while tropoelastin production is high during the mid- to late embryonic periods, it ceases in adulthood, although synthesis can be initiated by injury. Indeed, the notable absence of elastin in adult wound healing, despite its increased expression at the point of injury, which is characterized by scaring and contractures is in stark contrast to fetal scar-free healing where tropoelastin, although abundant, is not completely incorporated into elastic fibers. ${ }^{[75]}$

As such, within the context of the tissue engineering and regenerative medicine, it is important to understand and harness the properties of tropoelastin in the development of 
biomaterials, particularly ECM-inspired ones. Tropoelastin is a soluble $60-70 \mathrm{kDa}$ protein secreted by elastogenic cells (such as fibroblasts, endothelial cells, smooth muscle cells, chondrocytes and keratinocytes). Crosslinking of tropoelastin monomers results in the formation of insoluble elastin. Several excellent reviews about tropoelastin and elastin have been reported in literature. ${ }^{[72,76-79]}$

\subsection{Tropoelastin}

Since elastin is formed from tropoelastin by way of a self-assembly process with crosslinking, a detailed consideration of the properties of the latter is necessary. The properties of tropoelastin have been summarized hereinafter based on the excellent review by Mithieux et al. ${ }^{[77]}$

\subsubsection{Structural Properties}

Structural, tropoelastin has a flexible and asymmetric conformation in solution, which is characterized by an extended molecular body and two protruding legs (Figure 2a). ${ }^{[80,81]}$

The main feature of the sequence of amino acids in tropoelastin is the alternating hydrophobic and hydrophilic domains (Figure 2b). ${ }^{[76]}$ The hydrophobic domains mainly comprise of the non-polar glycine $(\mathrm{G})$, proline $(\mathrm{P})$, valine $(\mathrm{V})$ and alanine $(\mathrm{A})$ amino acid residues typically occurring in repeat amino acid combination motifs of GV, GVA, and PGV, with GVGVP, GGVP and GVGVAP repeats being the most common. ${ }^{[82]}$ The hydrophilic domains are characterized by high alanine and lysine (K) content that contributes to the intra- and intermolecular crosslinking. Typically, the hydrophilic domain features two or three lysines flanked by alanines (KA-type domains) or prolines and glycines (KP-type domains). There are approximately 40 lysine residues in secreted tropoelastin and all but five are modified by lysyl oxidase 
(LOX) for crosslinking. This high degree of crosslinking contributes to the stability and insolubility of the elastin. ${ }^{[83]}$

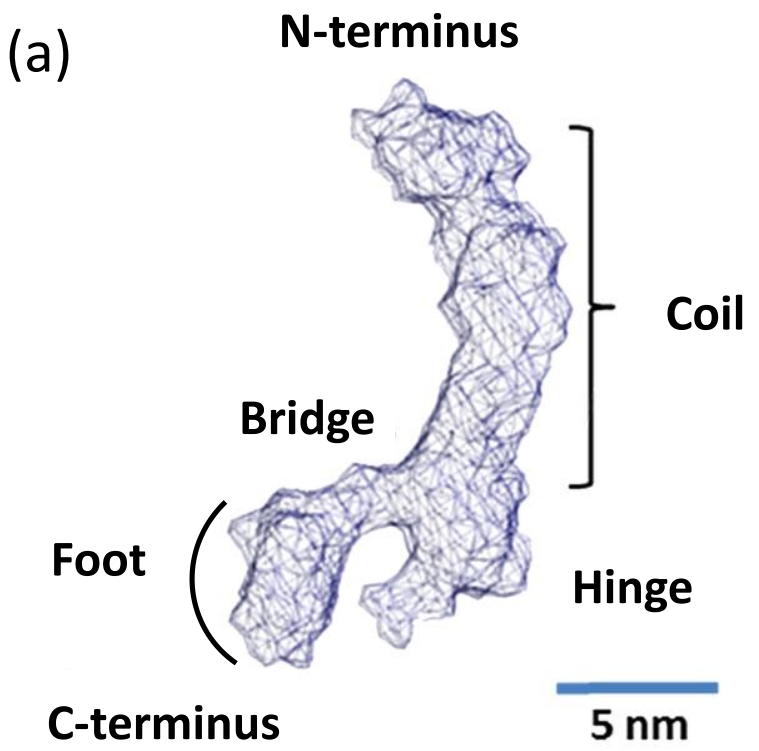

(b)

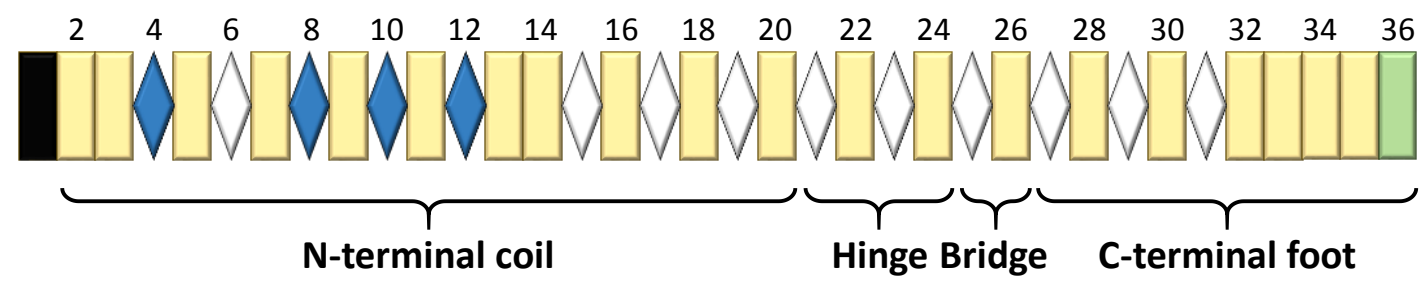

Figure 2. Schematic representation of the (a) tropoelastin monomer shape in solution and (b) amino acid sequence domain arrangement. Yellow rectangles and blue diamonds represent hydrophobic and crosslinking domains, respectively. Blue and white diamonds correspond to KP- and KA-type crosslinking domains, respectively. Domains 1 (signal sequence) and 36 (C-terminal containing two cysteine residues) have been marked in black and green, respectively. Adapted with permission. ${ }^{[77,84]}$ Copyright 2013, Elsevier. 
Several regions can be distinguished in the molecule, including an N-terminal coil, hinge, bridge and the C-terminal foot (Figure $2 b) .{ }^{[85]}$ They all contribute to the correct coacervation process and elastogenesis as well as in cellular recognition. This amino acid arrangement is highly conserved with $>70 \%$ similarity across different mammals and strict sequence preservation for splice junction and crosslinking regions and less so for hydrophobic motifs. ${ }^{[76,86]}$ Indeed, local mutations in the sequence result in global modifications that may disrupt the shape of the molecule and potentially alter the exposure of the bioactive motifs and the final functional assembly into the elastic fiber. ${ }^{[87-89]}$

The N-terminal coil region provides elastic properties to tropoelastin in its uncrosslinked state and is associated with the regulation of self-assembly and crosslinking during elastogenesis. ${ }^{[85]}$ The hinge and bridge regions are highly flexible and also contribute to elastic fiber assembly and mechanical coupling. ${ }^{[89,90]}$ During elastogenesis, monomer elasticity is propagated according to a head-to-tail model of fiber assembly in which the bridge region plays a crucial role in the orientation of the $\mathrm{C}$ terminal region. ${ }^{[90]}$ Finally, the C-terminal foot region is mainly characterized by two motifs involved in elastic fiber assembly and in cell-adhesion: the cationic GRKRK peptide that terminates the sequence, and the intramolecular disulfide bond between the only two cysteine residues of the molecule. C-terminal region facilitates cell adhesion through the contact with GAGs and the integrin-mediated recognition. ${ }^{[84,85]}$

\subsubsection{Self-assembly and Elastogenesis}

Elastic fiber formation during elastogenesis has been a topic of research for many years.

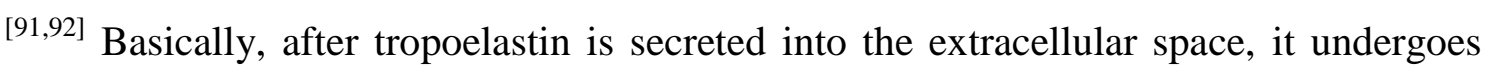
coacervation and self-assembles into nanoparticles that evolve into 1-2 $\mu \mathrm{m}$ spherical microaggregates that are subsequently transferred to microfibrils. Tropoelastin self- 
assembly is the result of temperature-induced specific interactions between hydrophobic domains and promotes exposure of the crosslinking motifs on the surface of the globular aggregates. $^{[85]}$

Elastic fibers also include fibrillin-rich microfibrils that are temporally associated with several ECM proteins. During elastic fiber assembly, microfibrils act as a structural and organizational template where tropoelastin microspherules are hierarchically incorporated into microfibril templates. The subsequent crosslinking by LOX enzymes gives rise to the elastic fibers with a well-defined order and alignment of the highest level of hierarchical assembly (Figure 3). The resulting microfibrils also play an important role in tissue homeostasis, providing bioactive cues to cell adhesion and regulating growth factor gradients. ${ }^{[93]}$

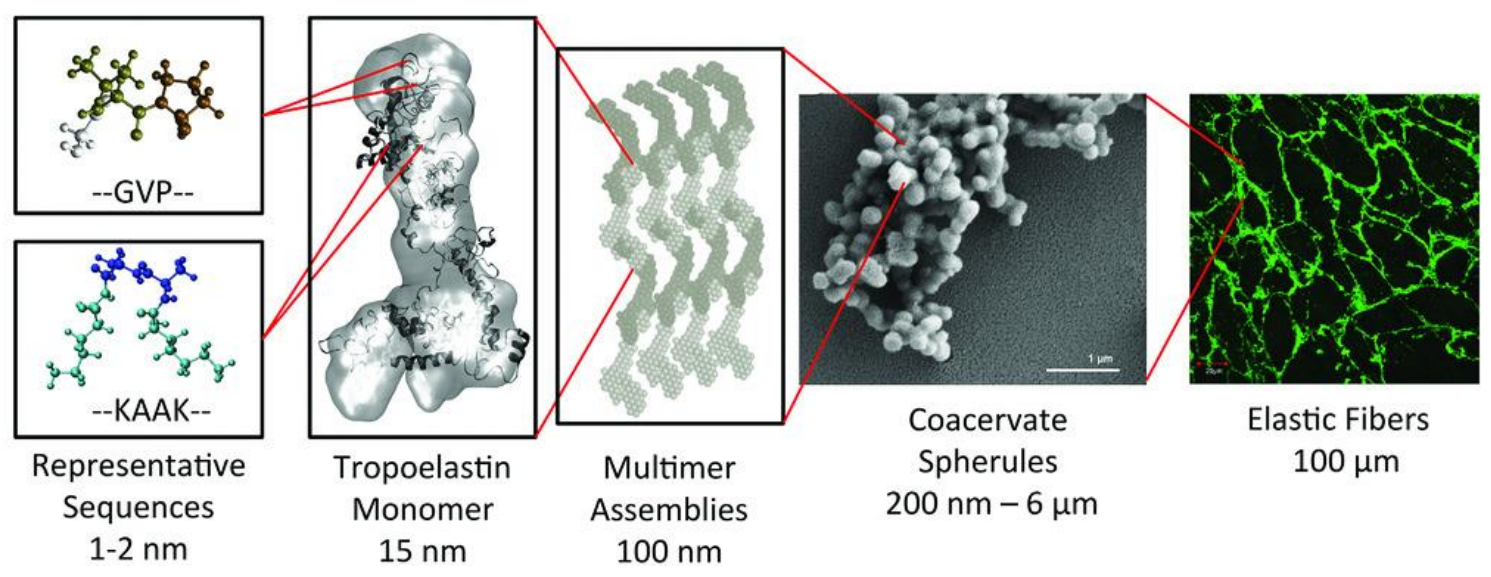

Figure 3. Schematic representation of the assembly of a tropoelastin monomer through defined stages, resulting in increasingly sophisticated intermediates and crosslinked elastic fibers. The scheme begins with the tropoelastin domains (left) and finishes with the elastic fiber network (right). Reproduced with permission. ${ }^{[81]}$ Copyright 2019, WILEY-VCH. 
The process of elastogenesis ends when the resulting elastic fibers are associated and interpenetrated with other structural proteins such as fibrillary collagen and fibronectin. ${ }^{[75]}$ The nature of this association, and the microarchitecture of the elastic fibers, strongly affects the resulting mechanical properties of the tissue such as elasticity and contractibility (mainly associated with aligned fibers), and stiffness and stressbearing (mainly associated randomly oriented fibers). ${ }^{[94]}$ Moreover, since elastin architecture is determined at an amino acid sequence level, the variation in the bioactive motifs that can be linked to the protein affords myriad biochemical properties, some of which are unique to particular tissues. As such, in the development of 3D-scaffolds that seek to simulate native tissues, it is important to take into account these different features. In this regard, a flexible technological platform that allows the endowment of these different features in the protein assembly is ideal.

\subsubsection{Mechanical Properties}

Elastin is not homogeneously spread within and across different tissues and the variation in the amount and nature of its structural organization, amount and nature of association with other structural and non-structural proteins affects the mechanical integrity and behavior of tissue. ${ }^{[95]}$ In contrast, the recoil property of a single tropoelastin molecule remains unaffected with near ideal spring qualities characterized by an impressive elastic behavior. ${ }^{[80]}$ In experiments involving multiple stretch and relaxation cycles, tropoelastin was found to be able to extend roughly eight times its length, with a Young's modulus of about $3 \mathrm{kPa}$ with no hysteresis. A worm-like chain model has been proposed to model this single chain elastin property (Figure 3). ${ }^{[78,81]}$

The crosslinking of tropoelastin monomer into the elastin fibers reduces its ability to extend and increases its stiffness. ${ }^{[96]}$ In a study summarizing the Young's moduli of different constructs of either tropoelastin alone or a composite of tropoelastin with other 
materials, ${ }^{[77]}$ a fairly broad range (up to $20 \mathrm{MPa}$ ) was observed. This suggests tunability of the mechanical properties depending on the type and degree of crosslinker and fabrication method. ${ }^{[80,97-99]}$ As such, the mechanics of native tissue (compliance and stiffness) can be mimicked in biomaterials development and resident cells would be able to sense the appropriate mechanical microenvironment to carry out their fundamental biological processes (proliferation, differentiation or apoptosis). ${ }^{[96,100,101]}$

\subsubsection{Cellular Interactions}

The interaction of tropoelastin with cells is mediated by the $67-\mathrm{kD}$ elastin-binding protein (EBP) on the cell surface, glycosaminoglycans (GAGs) and integrins, mainly $\alpha_{\mathrm{v}} \beta_{3}$ and $\alpha_{\mathrm{v}} \beta_{5} \cdot{ }^{\left[{ }^{[2,102]}\right.} \mathrm{EBP}$ is associated with the protective protein cathepsin A and binds to the consensus peptide sequence GXXPG. Thus, EBP is involved in the detection of elastic fiber damage and in the deposition of tropoelastin in the ECM. ${ }^{[77]}$ Conversely, GAG and integrin cell receptors mediate cell adhesion to tropoelastin and the subsequent spreading in a sequential process. First, GAGs attach to the central region (peptide 302-322) of tropoelastin and facilitate integrin-mediated cell adhesion. In this regard, integrin $\alpha_{v} \beta_{5}$ binds specifically to the central region (domains 17 and 18) and integrin $\alpha_{v} \beta_{3}$ to the charged C-terminal motif GRKRK (located in domain 36). ${ }^{[82,103]}$

Finally, and as an overall comment, since tropoelastin incorporates elastic and cellinteractive segments in its structure, this ECM component can be considered to be a multifaceted biocompatible molecule, performing and mimicking some of the important functions of the elastin matrix. ${ }^{[77]}$

\subsection{Relationship between Intrinsic Disorder and Elasticity}

Whereas collagen shows an ordered, triple helix structure, ${ }^{[104]}$ elastin is characterized by a significant conformational disorder, which contributes to its flexible and stretchable 
properties. ${ }^{[105,106]}$ The amino acid sequence of tropoelastin is responsible for this conformational disorder and the mechanical properties of elastin. Indeed, the crosslinking of elastin monomers, tropoelastin, provides stability and strength to the matrix and the hydrophobic domains contributing to self-aggregation and extensibility. ${ }^{[105,106]}$ At a sequence level, two main features are characteristic of elastin as an intrinsically disordered protein (IDP): ${ }^{[105,107]}$ (1) low complexity sequence and (2) proline and glycine content.

The sequence of tropoelastin is characterized by the repetition of low complexity protein motifs, including PG and GG amino acid motif tandems, associated with the formation of $\beta$-turns. Nevertheless, a huge volume of experimental and computational results indicates the absence of an ordered or repetitive structure. ${ }^{[88,108-110]}$ This is consistent with the well-established relationship between low sequence complexity and structural disorder. ${ }^{[111]}$

The proline and glycine content in elastin is another characteristic that is crucial for maintaining hydration of the protein backbone and subsequent conformational disorder. Indeed, it has been suggested that the presence of proline provides structural rigidity that induces conformational restrictions. This reduces the chain's ability to form stable hydrogen-bonded turns and $\beta$-sheets. ${ }^{[112]}$ In contrast, the conformational flexibility associated with the presence of glycine provides spatial mobility, which can favor ordered and disordered structures. Generally, an increased composition of proline and glycine can promote structural disorder through self-interactions, that would subsequently impede the formation of amyloid-like structures. Depending on the ratio between these two amino acids, Rauscher and Pomes established an approximate threshold to predict the structural order of the sequence, differentiating between amyloid-like and elastomeric proteins. ${ }^{[12,113]}$ 
An entropic origin has also been suggested as the key driving force sustaining the elastic properties of elastin. ${ }^{[114]}$ In this regard, when the protein is hydrated, the disorder in the system is decreased if the material is stretched. However, if the deformation force disappears, elastic relaxation takes place driven by the recovery of maximum entropy (entropic spring). However, the molecular basis of this elasticity has not been fully explained in detail and consensus has not been reached on whether elastin is isotropic, and lacking structure, or anisotropic with regions of order. ${ }^{[115]}$ Nonetheless, several models have been proposed to describe the mechanism of elasticity ${ }^{[79]}$ and they include random chain, ${ }^{[116]}$ liquid drop, ${ }^{[117,118]}$ and coiled-coil models. ${ }^{[119]}$

The hydrophobic domains in tropoelastin, which contain proline-glycine pairs that can adopt a $\beta$-turn conformations in solution, are mainly responsible for its elastic properties. However, fibrillar models have also been proposed, with Urry et al. suggesting that regular $\beta$-spiral structures based on repetitive and stable $\beta$-turns give rise to elasticity. ${ }^{[120]}$ Tamburro et al., in turn, suggested a freely fluctuating elastin chain in which dynamic glycine-based $\beta$-turns slide along the protein chain. ${ }^{[121]}$ The presence of transient secondary structures is consistent with a model in which the hydrophobic domains in elastin are disordered in the coalescent state, although not randomly.

Solid-state NMR and circular dichroism (CD) and Raman spectroscopic studies, in combination with recent studies using molecular dynamic simulations, ${ }^{[110,112,122,123]}$ confirmed the presence of an ensemble of fluctuating secondary structures with intrinsic disorder within the hydrophobic domains. As such, an emerging consensus gave rise to a new model for elastin in which it is classified as intrinsically disordered protein (IDP). This provides a unified view of elastin's structure and function. ${ }^{[105,106,108,110,124]}$ First, elastic recoil and resilience are related to a certain degree of disorder inside the tropoelastin molecule after coacervation. And second, tropoelastin self-assembly into 
microfibrils during the elastogenic process generates order on a large scale. Thus, since tropoelastin is incorporated into the ECM via coacervates, structural disorder, and hence elastic recoil and resilience, is preserved. In the same vein, tropoelastin coacervate can be considered as a liquid in that individual chains are in a maximally disordered state (melt-like state), but not randomly. ${ }^{[110]}$ In addition, and on average, the protein backbone remains highly hydrated, with the hydrophobic chains being buried in the aggregate, although no compact or water-excluding core is formed.

\subsection{Tissue Repair and Regeneration based on Engineered Tropoelastin}

Several procedures can be used to incorporate elastin into artificial scaffolds for tissue repair and regeneration. In addition to the use of decellularized tissues and hydrolyzed animal elastin approaches, ${ }^{[125-127]}$ the use of tropoelastin-based biomaterials is an interesting strategy to incorporate the benefits of elastin into engineered constructs. This solution is especially attractive since recombinant human tropoelastin is accessible.

The noticeable advantages associated with tropoelastin include exceptional mechanical properties, ability to interact with cells, and flexible manufacturing techniques. crucially, the inherent elastic properties, with associated bioactive properties unique to tropoelastin can be advantageous given that elastin expression and regeneration is highly reduced in adult tissue. ${ }^{[77]}$

As mentioned above, tropoelastin provides mechanical support and bioactive cues that can be transduced to cells. Thus, tropoelastin can act as a cell behavior modulator when immobilized onto a template surface through covalent crosslinking or physisorption. This surface coating has been shown to favor fundamental cellular processes of fibroblasts, ${ }^{[128-131]}$ endothelial cells, ${ }^{[132]}$ smooth muscle cells, ${ }^{[133]}$ and vascularization. ${ }^{[134]}$ In addition, cell binding, which has been linked to the C-terminus of 
tropoelastin, can be switched by adjusting the wettability of tropoelastin,. ${ }^{[130]}$ This "tropoelastin switch" allows for the definition of cell-selective spatial regions. ${ }^{[128]}$

Aghaei-Ghareh-Bolagh et al. have reported a hybrid film based on the combination of tropoelastin and silk that is intended for use as an acellular substrate for corneal replacement with outstanding optical properties. ${ }^{[129]}$ Both corneal epithelial and endothelial cells showed growth and normal function when supported by the film. Moreover, its intrinsic flexibility enables it to present its bioactive sequences to cell receptors, even in solution. Recently, Yeo and Weiss described the potential of this film as a proliferative and cell-attractive soluble factor, ${ }^{[73]}$ thus demonstrating that tropoelastin cell-binding domains can mediate cell fate irrespective of mechanotransduction. This highlights the potential use of tropoelastin in regenerative medicine for the repair of elastic tissues, including vasculature and skin.

\subsubsection{Recombinant Tropoelastin for Cardiovascular Applications}

Given that elastin is one of the major structural component of vascular tissues, tropoelastin is a promising candidate for developing biomaterials that can mimic the complex mechanical and biological matrix-cell interactions of natural ECM. This is necessary to improve the therapeutic efficacy of biomaterials for cardiovascular applications. ${ }^{[135-138]}$

Coating synthetic grafts with tropoelastin has been shown to successfully modulate thrombosis and smooth cell proliferation. ${ }^{[133,139]}$ Additionally, electrospun tropoelastin maintains its structural integrity, thus mimicking the requirements of native ECM and enhancing the growth of endothelial cells. A combination of electrospun tropoelastin and polycaprolactone (PCL) has been used to fabricate a biomaterial that mimic the internal part of the mammary artery. ${ }^{[140]}$ The resulting composite constructs increased 
the HUVEC adhesion and proliferation and a low platelet attachment. In addition, when these tropoelastin/PCL constructs were tested as carotid grafts rabbit models, they remained stable and retained their original elasticity even after 1 month of implantation. ${ }^{[72]}$

Recently, Wang et al. proposed the use of ice to form a sacrificial scaffold over which a fully functional polymer-based vascular construct could be assembled. ${ }^{[141]}$ in this regard, ice was 3D-printed and cast into small vessels scaffold (radius $<3 \mathrm{~mm}$ ). Given the simplicity of production, structural rigidity of ice several polymers, including tropoelastin and recombinant polymers thereof can be used to coat the rigid ice template, which when melted out would leave behind well-defined polymer based scaffold of blood vessels.

Tropoelastin has also been used in the development of coatings for the prevention of restenosis. A new generation of stents has been produced with surfaces coated with tropoelastin to enhance endothelialization, and reduce both thrombogenicity and smooth muscle hyperplasia. ${ }^{[142]}$ Indeed, it is well established that the covalent attachment of bioactive molecules, such as tropoelastin, onto the metal surfaces such as these stents is known to improve their mechanical properties, biocompatibility and hemocompatibility. ${ }^{[138,143,144]}$

Furthermore, recombinant DNA technology enables the introduction of specific changes into the tropoelastin sequence in order to endow bespoke biological properties, such as protease sensitivity to control biodegradation. Indeed, single mutations in tropoelastin have been reported to impart resistance to kallikrein and thrombin proteases. ${ }^{\text {[90] }}$

\subsubsection{Recombinant Tropoelastin for Dermal Applications}


While wound care and the use dermal substitutes has seen great improvements over the last decades, wound contraction, delayed healing and scarring remain a challenge. ${ }^{[145]}$ In efforts to develop dermal substitutes with improved applications, there is consensus that an ideal scaffold should not only facilitate wound closure but also restore native ECM and tissue functionality. One of the notable features of dermal scars is the absence of elastin, which is thought to be partly responsible for the stiffness and poor ECM organization in scar tissue. ${ }^{[146]}$ This is so because, wound healing in developing fetus is characterized by increased tropoelastin expression and scarless healing and restoration of normal skin structure and function. ${ }^{[74]}$

As such, it is logical that the inclusion of elastin or properties thereof should considered in the design and development of dermal substitute for wound healing applications. Moreover, given this clear need and the manufacturing versatility of tropoelastin, a lot of scaffolds, in different forms, such as 3D hydrogels and electrospun fiber meshes, have been widely reported in the literature. ${ }^{[97,137,147-150]}$ Some of the positive results observed with tropoelastin inclusion in wound healing application include the ability to speed up wound repair, enhance dermal regeneration and increase angiogenesis. ${ }^{[151]}$ Indeed, the improvement in commercial full thickness dermal substitutes reported by Weiss and coworkers is leading to the next generation of dermal substitutes. ${ }^{[152,153]}$ These authors have proposed a hybrid biomaterial (based on tropoelastin and fibroblasts) and a process for generating elastic fibers in tunable quantities. This prefabricated extensive elastic fiber network is meant to be surgically inserted in the appropriate location in the patient's deep dermis, where it acts as a dermal tissue regeneration template. ${ }^{[153]}$

In other studies, a sprayable and photocrosslinkable composite hydrogel adhesive based on gelatin methacryloyl (GelMA) and methacryloyl-substituted recombinant human 
tropoelastin (MeTro) has been tested in vivo and in vitro as a significant strategy for sutureless wound closure and healing. ${ }^{[154,155]}$ This hybrid construct also may incorporate cargo-antimicrobial peptides and its tunable mechanical properties can be modulated by polymer (GelMA/MeTro) ratios and total polymer concentrations, along with crosslinking type and time.

Additionally, stable dermal scaffolds can be fabricated with tropoelastin using a heatbased molding procedure (HeaTro). ${ }^{[156]}$ After dissolving and casting, tropoelastin constructs were stabilized by thermal crosslinking at $160{ }^{\circ} \mathrm{C}$. HeaTro grafts demonstrated the ability to promote dermal regeneration in mouse and pig models. The HeaTro scaffold accelerated wound healing by providing an ECM-mimicking environment that increase cellular infiltration, epidermis appearance, vascularization and improved collagen organization.

Very recently, Yeo et al. ${ }^{[157]}$ have developed a wound dressing for injured skin based on a polyurethane film with a surface activated by plasma immersion ion implantation in order to immobilize tropoelastin via covalent bonding. This wound patch was loaded with human multipotent adult progenitor cells, with tropoelastin playing a significant role of anchoring and promoting cell growth and phenotype.

\subsubsection{Recombinant Tropoelastin for other TERM Applications}

The multifaceted behavior of tropoelastin has allowed its use to be extended for the regeneration of other tissues. Indeed, tropoelastin has been shown to contribute to the behavior of many cell types, which include the guidance of neurites and Schwann cells, ${ }^{[158]}$ and the expansion of human bone-marrow derived stem cells. ${ }^{[96,159]}$

One of its promising application is as a surgical sealant. Annabi et al., for example, have demonstrated the sealing properties of MeTro and its potential use in surgery. ${ }^{[160]}$ 
Indeed, in vivo studies involving artery sealing in rats and complete sealing of leaking lung tissue in a pig model produced promising results that demonstrated the potential clinical efficacy of these tropoelastin-based formulations as surgical adhesives.

The photocrosslinkable composite GelMA/MeTro hydrogel has also shown neurosupportive properties and provides strong tissue adhesion. ${ }^{[161]}$ This hydrogel is intended for treatment of peripheral nerve repair since it acts as an elastic glue, a property that is adequate for neurite extension without affecting intended function.

Another example of the versatility of tropoelastin-based biomaterials is the wide range of macromolecules that can be bioconjugated to them. For example, graphene oxide (GO) nanoparticles have been added to MeTro to obtain a highly elastic and conductive MeTro/GO hybrid hydrogel. ${ }^{[162]}$ The ability of this hydrogel to conduct electrical current was verified by connecting pieces of abdominal muscles explanted from rats. The in vivo biocompatibility was assessed using samples implanted subcutaneously in rats.

Finally, magnetic properties have been used for tissue engineering. In this regard, Pesqueira et al. have reported the use of human recombinant tropoelastin doped with magnetically responsive iron particles to obtain sponge-like hydrogels for soft tissue regeneration by in situ precipitation. ${ }^{[163]}$ The secondary structure of tropoelastin was altered by the presence of these magnetic particles, with the hydrogels showing a smaller pore size and less swelling.

It has been reported that magnetically responsive materials regulate cell fate by allowing non-invasive external control. ${ }^{[164]}$ As such, this type of construct has been used for tissue repair applications. ${ }^{[165]}$ For instance, in vivo regeneration of muscle in mice or 
accelerated bone tissue formation in rabbits have been reported when the lesion site is stimulated magnetically. ${ }^{[166,167]}$

\section{Emergence of New Elastin-based Biomaterials: Elastin-like Recombinamers}

The challenge of tissue and organ engineering currently requires the development of innovative biomaterials that recapitulate the dynamics, biochemistry and structural features of native ECM. These materials must be biocompatible, bioactive, mimic the natural cellular microenvironment and allow appropriate mechanical and biological cell stimulation in order to modulate cell behavior. As such, knowledge from cell and molecular biology, biochemistry and materials science may be combined to develop 3D scaffolds with advanced features. These requirements have opened the way to recombinant protein polymers, including ELRs.

ELRs are a class of genetically engineered protein polymers based on the repetition of conserved motifs found in the hydrophobic domains of tropoelastin. ${ }^{[168]}$ As aforementioned, the interactions between these domains are responsible for reversible coacervation of tropoelastin and subsequent elasticity. The structural characterization of these hydrophobic domains enabled the identification of repetitive motifs that exhibit the properties of tropoelastin. ${ }^{[169]}$ For example, the repetition of tetra- (VPGG), penta(VPGVG) and hexa- (APGVGV) peptides in polymeric molecules has been shown to mimic the self-assembly and elastic mechanical properties of elastin (e.g. low stiffness, high resilience and extensibility). ${ }^{[78,168,170]}$ As such, it was possible to produce an ideal model for the fabrication of biosynthetic materials that mimic the unique physical properties of natural elastin. ${ }^{[105]}$

The most prevalent repetitive tropoelastin motif across species, the pentapeptide VPGVG, is the simplest repetitive motif that exhibit lower critical solution temperature 
(LCST) phase behavior with an inverse transition temperature below physiological temperature and viscoelastic behavior. ${ }^{[168,171]}$ As such, most ELRs comprise the pentapeptide repeat unit (VPGXG), where the guest residue (X) can be any amino acid except proline. This amino acid sequence flexibility, allowing for the addition of different amino acids to the pentapeptide, affords the precise tuning of the physicochemical properties (e.g. LCST) ${ }^{[172]}$ and presents a wide range of possibilities in the fabrication of biomaterials, including ECM mimetics.

In fact, other amino acids in the pentapeptide can also be replaced to impart desired physicochemical properties. For example, substituting glycine, located in third position in the pentapeptide VPGXG, with alanine changes the elastic response of ELRs to a plastic response due to the fact that polyVPAXG tends to form more stable secondary structures than polyVPGXG ${ }^{[173]}$ Crucially, both the plastic-like and elastic-like domains can be combined in the design of the molecule to produce ELRs that can be used to develop thermoplastic elastomers, thereby extending potential applications. ${ }^{[174,175]}$

Additional modifications can be introduced at the sequence level for the production of multifaceted polypeptides. Indeed, the biological (e.g. biocompatible, biodegradable) and mechanical properties (extensibility and elastic recoil) of ELRs can be synergistically combined with other functionalities to improve their cell-response. In this regard, Tirrell Lab demonstrated that ELRs can be used as polymeric platforms with modular design in combination with different interspersed peptide motifs. Integrinmediated binding domains from fibronectin were expressed within an ELR backbone in order to improve the cell attachment on ELR matrices. In this work, the peptide motif arginine-glycine-aspartic acid (RGD) was used to promote cell adhesion through the $\alpha_{5} \beta_{1}$ integrin receptor, ${ }^{[176]}$ and the arginine-glutamic acid-aspartic acid-valine (REDV) peptide was used specific attachment of endothelial cells through the $\alpha_{4} \beta_{1}$ integrin 
receptor. ${ }^{[177-179]}$ They demonstrated that cell-binding motifs density can be flexibly modulated as a function of cell adhesion and proliferation. ${ }^{[180]}$

The fabrication of ELRs with modular designs allows the production of biomimetic polymers with high level of control of their properties. The combination of alternating protein blocks allows to biofabricate a myriad of complex designs with exhaustive control of their properties. All of this combined with the intrinsic biocompatibility, biodegradability, stimuli-responsiveness and viscoelastic properties make ELRs a promising biomaterial. $^{[181]}$

\subsection{Synthesis of ELRs}

Although the first elastin-like polypeptides made by Urry et al. were produced by chemical methods, their complexity and large molecular weight necessitate the use of recombinant method to guarantee high yield of highly pure and monodisperse products. ${ }^{[182]}$ Genetic engineer techniques provide precise control of the sequence, chain length and stereochemistry of protein polymers. ${ }^{[172]}$ The number of techniques available is increasingly growing in parallel with progress in molecular biology. The most relevant methods for the design and synthesis of recombinant polymers has been reviewed by others elsewhere. ${ }^{[183]}$ Briefly, sequence control is usually obtained by the use of the polymerase chain reaction (PCR) or the directional ligation of the monomeric genes. In this sense, it is worth noting the powerful methods developed by Chilkoti Lab, which include the recursive directional ligation by plasmid reconstruction (PRe-RDL) method and the overlap extension rolling circle amplification (OERCA) method. ${ }^{[184,185]}$

Once the encoding gene is created, it is transformed into an expression organism. Although, multiple expression platforms are used for the expression of protein polymers, Escherichia coli is used preferentially due to cost-effectiveness and 
feasibility of scaling-up. ${ }^{[14]}$ The commercial availability of $\mathrm{T} 7$ based pET expression systems facilitates the heterologous expression. Typical expression yields of protein polymers on the order of 100 to $1000 \mathrm{mg} \mathrm{L}^{-1}$ of culture media have been reported. ${ }^{[186,187]}$ However, the implementation of antibiotic-free selection systems has been reported to enabled an increase in the yield to $12.8 \mathrm{~g} \mathrm{~L}^{-1},^{[188]}$ with a decrease in production costs. Crucially, recent studies about the industrial feasibility of the large-scale production of recombinant materials estimated the costs to range from $\$ 23$ to $\$ 761 \mathrm{~kg}^{-1}$ for $E$. coli optimized production plants. ${ }^{[189]}$ Moreover, it must be noted that the expression levels have a direct impact on the production costs. As such, biotechnological tools to improve protein expression are increasingly being developed due the interest in metabolomics and synthetic biology. This is expected to improve the efficiency of the technology with reduced production costs. In line with this, other organisms that can be used to produce protein polymers include yeasts, ${ }^{[190]}$ fungi ${ }^{[191]}$ and plants. ${ }^{[192]}$ Indeed, eukaryotic systems can provide, if needed, additional advantages regarding protein folding, extracellular secretory expression or translational modifications amongst others. ${ }^{[193]}$

After production, purification of elastin-like proteins is typically achieved by nonchromatographic methods that exploit the LCST phase behavior of the proteins. The thermally-driven phase transition constitute an important advantage for the costeffective purification of elastin-based polymers. It enables the purification by simple purification through inverse transition cycling (ITC). ${ }^{[194]}$ This method involves triggering the transition of the ELRs by temperature or by the addition of salts into a precipitate, which is then separated by centrifugation. The precipitate is then resuspended in cold water or buffer. Repeating this sequence allows the attainment of highly pure biomaterials cost effectively as it also does not required high technical skill or equipment. ${ }^{[13]}$ 


\subsection{ELR-based 3D Scaffolds for TERM Applications}

In recent years, engineered scaffolds based on ELRs have been extensively studied for their use in TERM. As a function of the molecular design and the crosslinking strategy, the viscoelastic properties of ELR-based scaffolds can be tuned precisely in order to mimic the ECM of multiple tissues. ${ }^{[71]}$ For instance, hydrogel scaffolds can be obtained by exploiting either the polymer thermal behavior and physical interactions, or exploiting the formation of covalent bonds between reactive groups or a combination of both. This design flexibility allows for a wide array of advanced-design features.

\subsubsection{Physically Crosslinked Elastin-like Scaffolds}

First, given the reversible smart behavior of elastin-like polymers, amphiphilic block co-polymers based on ELRs have been investigated for the production of physically crosslinked hydrogels. Rational design of elastin-like block co-recombinamers enables the production of physically crosslinked 3D networks under physiological conditions. By alternating blocks with different hydropathies, and as a consequence LCSTs, it is possible to modulate the selective self-assembly of hydrophobic blocks. The hydrophobic forces between the coacervated blocks drive the formation of the hydrogel through microphase separation (Figure 4). In this regard, it is important to note the studies developed by Conticello, Chaikof and coworkers on the nanostructuration of amphiphilic ELRs with multiblock designs and the mechanical properties of the subsequent hydrogels. ${ }^{[173,195]}$

The hydrophobically crosslinked moieties form transient secondary structures above the transition temperature, thus remaining highly hydrated. ${ }^{[110]}$ In fact, thanks to this intrinsic structural disorder, ELRs show their characteristic elastic recoil and phase behavior. ${ }^{[105,109,196]}$ The lack of ordered and stable structures results in a dynamic 
response of the ELR chains within the hydrogel and their evolution into entropically more stable, soluble nanostructures.

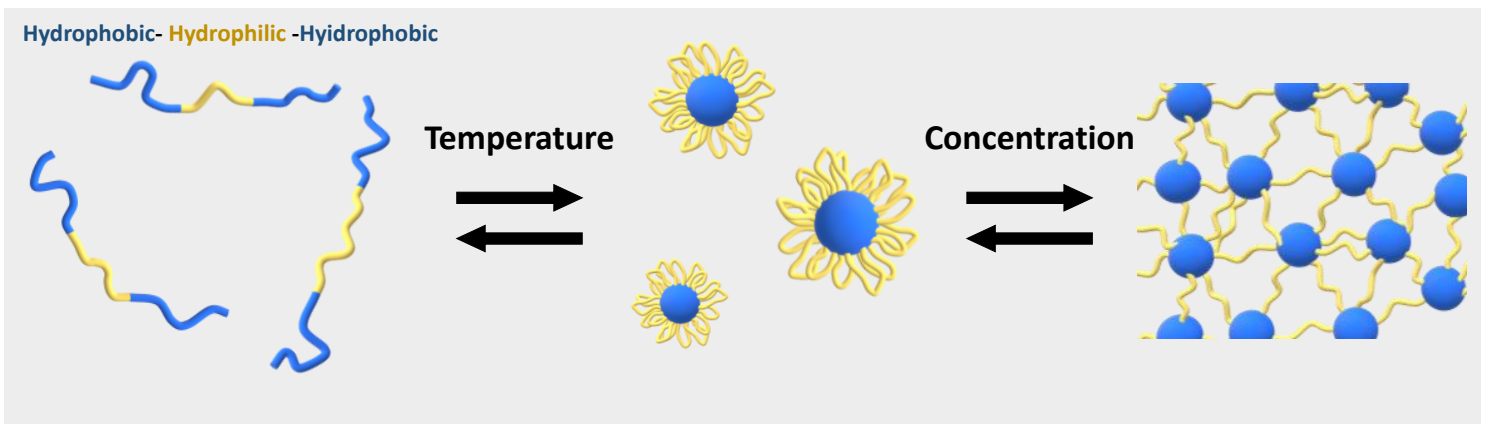

Figure 4. Amphiphilic multiblock ELRs self-assemble into nanostructures that can evolve to physical hydrogels as a function on the concentration.

Although hydrophobically crosslinked hydrogels are not stable in solution, they can be stabilized in solution by incorporating additional self-assembling domains (SADs). Interesting biomaterials with customized properties can be achieved by combining ELRs with order-promoting protein domains (Table 1) such as leucine zippers, ${ }^{[197]}$ coiled-coils, ${ }^{[198,199]}$ or SADs from other structural proteins, such as silk or resilin. ${ }^{[200-204]}$ Additionally, self-assembling properties of different SADs can converge synergistically leading the formation of physical hydrogels with improved features. For instance, an innovative bioink has been fabricated by the rational combination of silk-like blocks, leucine zippers and ELRs: ${ }^{[205]}$ In this arrangement, silk domains promote the formation of highly stable and insoluble $\beta$-sheets, thus imparting thermal and mechanical resistance; leucine zipper-containing motif self-assembles into $\alpha$-helical structures that dimerizes specifically; and the amphiphilic elastin-like block co-recombinamer undergoes thermal coacervation. The combination of the three SADs converged in a sequential stabilization process of the 3D hydrogel network, thus providing good printability and long-term stability. 
Table 1. Protein motifs employed in the development of self-assembling ELR-based biomaterials.

\begin{tabular}{|c|c|c|c|}
\hline $\begin{array}{l}\text { Self-assembling } \\
\text { domain }\end{array}$ & Sequence & Characteristic & Ref. \\
\hline Silk-like motifs & $(\text { GAGAGS })_{n}$ & $\begin{array}{l}\text { Hard crystalline domain } \\
\text { Irreversible } \beta \text {-sheet formation } \\
\text { Strength and structure }\end{array}$ & {$[200-203]$} \\
\hline Resilin-like motifs & $(\text { QYPSDGRG })_{n}$ & $\begin{array}{l}\text { Rubber-like protein } \\
\text { UCST phase behavior } \\
\text { Elasticity }\end{array}$ & [204] \\
\hline Leucine zippers & $\begin{array}{l}\text { KENQIAIRASFLEKENSALRQEVA } \\
\text { DLRKE(L/C)GKCKNILAKYEA }\end{array}$ & $\begin{array}{l}\text { Stable dimeric coiled-coil } \\
\text { interactions }\end{array}$ & {$[197,206]$} \\
\hline $\begin{array}{l}\text { Cartilage oligomeric } \\
\text { matrix protein } \\
(\mathrm{COMPcc})\end{array}$ & $\begin{array}{l}\text { GDLAPQMLRELQETNAALQDVRE } \\
\text { LLRQQVKEITFLKNTVMESDASGK } \\
\text { LN }\end{array}$ & $\begin{array}{l}\text { Coiled-coil domain based on } \\
\text { five identical } \alpha \text {-helices and a } \\
\text { central hydrophobic pocket for } \\
\text { hydrophobic molecule binding }\end{array}$ & {$[198,199]$} \\
\hline Poly-Ala & $(\mathrm{A})_{\mathrm{n}}$ & $\alpha$-helix formation & {$[207]$} \\
\hline
\end{tabular}

Aromatic aa-Glycine- $\quad\left(\mathrm{XG}_{\mathrm{n}}\right)_{\mathrm{m}}, \mathrm{X}=$ aromatic aa Hydrophobic interactions, $\pi-\pi$ [208,209] rich peptides stacking interactions

\begin{tabular}{llll}
\hline Viral capsid proteins & $\begin{array}{l}\text { Capsid protein from the Cowpea } \\
\text { chlorotic mottle virus (CCMV) }\end{array}$ & $\begin{array}{l}\text { pH-sensitive specific self- } \\
\text { assembly }\end{array}$ & {$[210]$} \\
\hline Amyloidogenic ELPs & $\mathrm{X}_{1} \mathrm{GGX}_{2} \mathrm{G}\left(\mathrm{X}_{1,2}:\right.$ V or L) & $\begin{array}{l}\text { Amyloid-like fiber formation } \\
\text { Cell-binding motif }\end{array}$ & {$[211]$} \\
\hline
\end{tabular}

Bespoke physical hydrogels can be produced by controlling the balance of molecular order-disorder characteristic of molecule. In line with this, a multimodular design combining ELR and poly-alanine domains has been used to develop physical hydrogels with improved stability for use as biocompatible injectable scaffolds for tissue regeneration. ${ }^{[207]}$ In this work, the poly-alanine domains self-assembled into ordered $\alpha$ helices and were used to stabilize ELR coacervation, which drove the formation of 
porous 3D scaffolds. Hydrogel porosity was then modulated by varying the recombinamer concentration and stiffness and LCST behavior were tuned by varying the helix percentage and ELR composition. ${ }^{[207]}$ The resulting 3D scaffolds remained stable after 21 days in vivo in mice models, where they promoted cell migration and proliferation, as well as vascularization. This study highlights the benefits of controlling the order-disorder balance in the scaffold in order to control the architecture, viscoelastic behavior and stability of the hydrogel, which are crucial parameters for cell response. ${ }^{[212]}$

In addition, given that molecular orientation is crucial for the induction of mineral deposition in scaffold, ${ }^{[213]}$ the order-disorder balance in the ELR-based scaffolds presents a platform through which relevant biological processes, including biomineralization, can be controlled. in this regard, the control of order-disorder balance in ELR was successfully used to create scaffolds that mimic the structure of collagenous matrices in hard tissues, ${ }^{[213,214]}$ as well as develop a model for arterial calcification. ${ }^{[215]}$

\subsubsection{Chemically Crosslinked Elastin-like Scaffolds}

Another successful strategy for creating ECM-inspired stable hydrogels with tunable architectures and mechanical properties involves the covalent crosslinking of ELR molecules, which allows higher levels of stiffness and precise control of the elasticity of the scaffold to be achieved (Table 2). Given the versatility of ELRs, different side chain groups can be used for crosslinking using either enzymes or addition of a soluble or tethered crosslinker. In enzymatic crosslinking, amine-containing side groups can be linked to other residues enzymatically, for example glutamine amine groups crosslinked by tissue transglutaminase activity. ${ }^{[216]}$ However, this approach can be affected by other factors such as temperature, $\mathrm{pH}$ and concentration. Moreover, it also affords limited 
control on modular crosslinking. Some of these drawbacks are avoided by introducing soluble crosslinkers or tethering chemical crosslinkers to the ELR. ${ }^{[217,218]}$ However, while commonly used homofunctional crosslinkers such as glutaraldehyde, ${ }^{[219]}$ diisocyanates, ${ }^{[220]}$ propionic acids, ${ }^{[221]} \mathrm{N}$-hydroxysuccinimide esters, ${ }^{[222]}$ methacrylates, ${ }^{[223]}$ can be used, their reactionary by-products are cytotoxic. ${ }^{[224]}$ Moreover, the reactions of most homofunctional crosslinkers start as soon as they are added and progress rapidly with reaction kinetics that can take as long as the mixing process leading to poor crosslinking homogeneity. ${ }^{[224]}$ These draw-backs of toxicity and poor reaction control can be solved by using catalyst-free click chemistry. Indeed, with click-chemistry, particular side groups (i.e. amine groups in lysine) can be functionalized with click-reactive groups to a predetermined degree of substitution used to produce biocompatible and stable hydrogels in the absence of chemical crosslinkers or catalysts. ${ }^{[217,225]}$ Other ELR side groups, other than amines, that can be used for crosslinking include carboxyls from glutamic acids, ${ }^{[26]}$ hydroxyphenylalanines from tyrosines, ${ }^{[227,228]}$ methylsulfanyl from methionines or thiol groups from cysteines. ${ }^{[229,230]}$ Depending on the nature of the covalent bond, crosslinking can be triggered by physicochemical stimuli, such as mild oxidative microenvironments or UV radiation. ${ }^{[231,232]}$ Moreover, the incorporation of non-canonical amino acids and other motifs, such as metal-binding motifs, ${ }^{[233]}$ extends the applicability of these recombinant biopolymers in the manufacture of chemically crosslinked hydrogels. ${ }^{[234,235]}$

Table 2. Potential strategies to fabricated chemically crosslinked ELR-based scaffolds with tunable properties for TERM.

\begin{tabular}{|c|c|c|c|c|}
\hline Molecular design & Crosslinking strategy & Mechanical properties & Application & Ref. \\
\hline Interspersed amine & Chemical crosslinker: & Tunable stiffness & Soft tissues & {$[236-$} \\
\hline groups in the ELR & tetrakis(hydroxymethyl)phosphon & (storage moduli $\sim 250 \mathrm{~Pa}$ to & regeneration & 239] \\
\hline
\end{tabular}




\begin{tabular}{|c|c|c|c|c|}
\hline & ium chloride (THPC) & $\sim 2,200 \mathrm{~Pa})$ & & \\
\hline $\begin{array}{l}\text { Interspersed amine } \\
\text { groups in the ELR }\end{array}$ & $\begin{array}{l}\text { Strain-promoted azide-alkyne } \\
\text { cycloaddition (SPAAC) }\end{array}$ & $\begin{array}{l}\text { Tunable stiffness } \\
\text { (storage moduli } \sim 100 \mathrm{~Pa} \text { to } \\
\sim 10,000 \mathrm{~Pa} \text { ) }\end{array}$ & $\begin{array}{l}\text { Soft and hard } \\
\text { tissues regeneration }\end{array}$ & $\begin{array}{l}{[217,2} \\
25,240 \\
]\end{array}$ \\
\hline $\begin{array}{l}\text { Interspersed } \\
\text { hydroxyphenylalanines } \\
\text { groups in the ELR }\end{array}$ & $\begin{array}{l}\text { Modification of } \\
\text { hydroxyphenylalanines groups } \\
\text { into 3,4-dihydroxyphenylalanine } \\
\text { (DOPA) }\end{array}$ & $\begin{array}{l}\text { Dry adhesion strength }(>2 \\
\mathrm{MPa}) \\
\text { Wet adhesion strength } \\
(\sim 0.24 \mathrm{MPa})\end{array}$ & Tissue sealant & [241] \\
\hline $\begin{array}{l}\text { Interspersed thiol } \\
\text { groups in the ELR }\end{array}$ & $\begin{array}{l}\text { Induction of S-S bonds with mild } \\
\text { oxidative conditions }\end{array}$ & $\begin{array}{l}\text { Tunable stiffness } \\
\text { (storage moduli } \sim 10 \mathrm{~Pa} \text { to } \\
\sim 100 \mathrm{~Pa} \text { ) }\end{array}$ & $\begin{array}{l}\text { Soft tissues } \\
\text { regeneration }\end{array}$ & {$[230]$} \\
\hline $\begin{array}{l}\text { ELR1 with SpyTags } \\
\text { ELR2 with } \\
\text { SpyCatchers }\end{array}$ & $\begin{array}{l}\text { Spontaneous induction of } \\
\text { isopeptide bonds }\end{array}$ & $\begin{array}{l}\text { Tunable stiffness } \\
\text { (storage moduli } \sim 30 \mathrm{~Pa} \text { to } \\
\sim 300 \mathrm{~Pa} \text { ) }\end{array}$ & $\begin{array}{l}\text { Soft tissues } \\
\text { regeneration }\end{array}$ & [242] \\
\hline $\begin{array}{l}\text { Amine groups flanking } \\
\text { the ELR }\end{array}$ & $\begin{array}{l}\text { Chemical crosslinker: 4-arm } \\
\text { PEG/NHS }\end{array}$ & $\begin{array}{l}\text { High extensibility (up to } \\
1500 \% \text { ) }\end{array}$ & $\begin{array}{l}\text { Elastic tissues } \\
\text { regeneration (blood } \\
\text { vessels, skin, lung, } \\
\text { cardiac tissues) }\end{array}$ & [218] \\
\hline $\begin{array}{l}\text { KCTS motifs flanking } \\
\text { the ELR }\end{array}$ & Photoinduced S-S bonds & $\begin{array}{l}\text { High extensibility (up to } \\
420 \% \text { ) } \\
\text { Tunable tensile strength }\end{array}$ & $\begin{array}{l}\text { Elastic tissues } \\
\text { regeneration (blood } \\
\text { vessels, skin, lung, } \\
\text { cardiac tissues) }\end{array}$ & [232] \\
\hline $\begin{array}{l}\text { Interpenetrated } \\
\text { networks of Zn-binding } \\
\text { motifs-containing } \\
\text { ELRs and covalently } \\
\text { crosslinkable ELRs }\end{array}$ & $\begin{array}{l}\text { Reversible crosslinking ( } \mathrm{Zn} \\
\text { coordination and hydrophobic } \\
\text { interactions) combined with } \\
\text { covalent crosslinking with THCP }\end{array}$ & $\begin{array}{l}\text { High strength }(>2.5 \mathrm{MPa}) \\
\text { Toughness }\left(>1300 \mathrm{~J} \mathrm{~m}^{-2}\right) \\
\text { Stretchability }(>500 \%) \\
\text { Self-adhesion }\end{array}$ & Tissue sealant & [233] \\
\hline
\end{tabular}

\subsection{Biofunctional ELR-based Scaffolds}


As mentioned previously, 3D scaffolds for tissue engineering that seeks to mimic natural ECM must provide specific microenvironments able to guide cell behavior. As such, the internal architecture, biological, mechanical and biodegradation properties are key parameters governing cellular activities such as adhesion, migration, proliferation or differentiation (Figure 5). ${ }^{[243-245]}$ In this sense, given the reciprocal nature of the interaction between the natural ECM and cells, an ideal scaffold should exhibit a dynamic behavior that promotes communication with cells. In addition, they should respond to cell signals and should be tunable in order to be able to customize them for different tissue requirements.

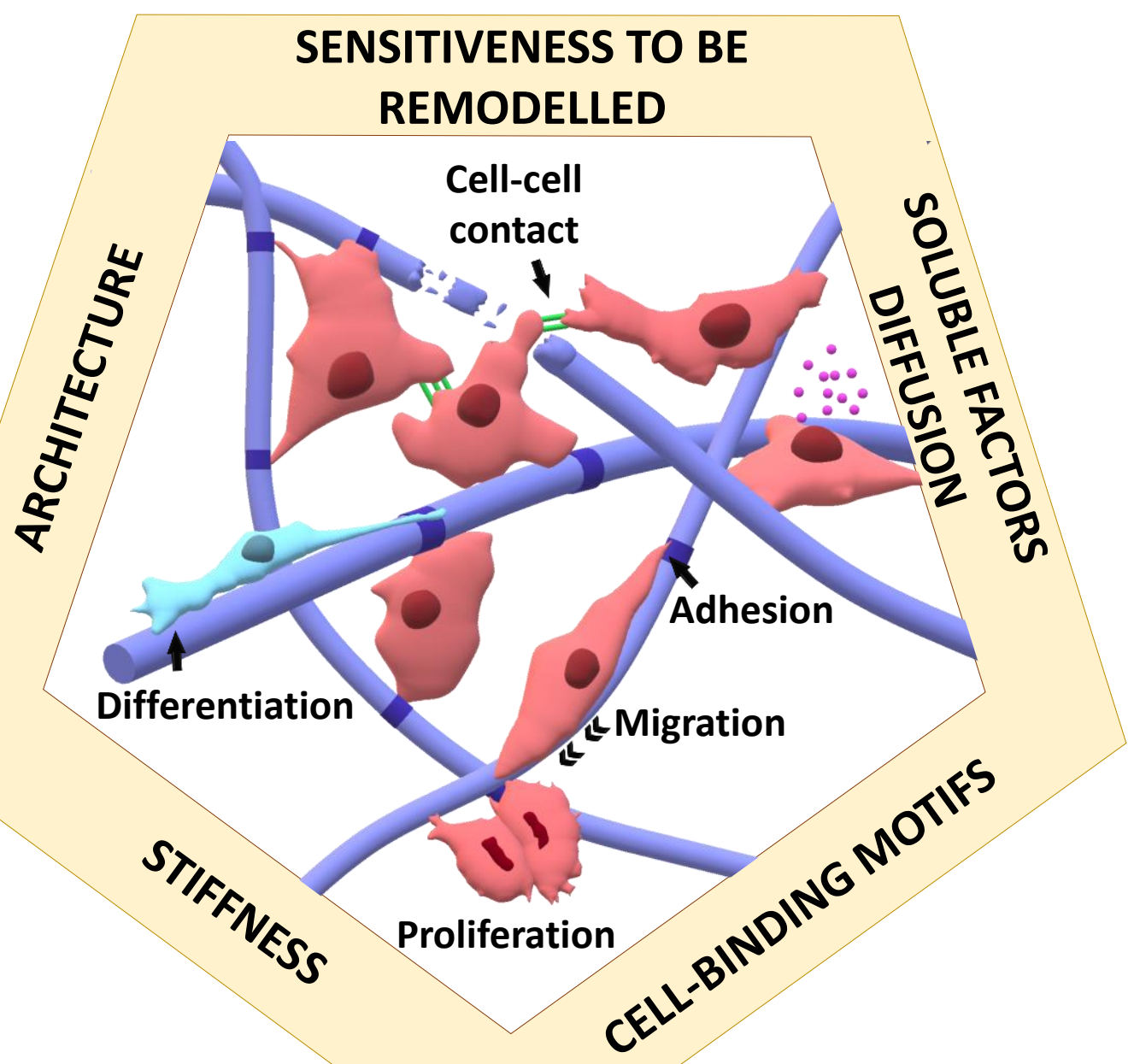


Figure 5. Schematic representation of the different ECM features influencing cell behavior. Biofabrication of scaffolds for TERM based on ELRs with modular design allows for precise control of the mechanical, topographical and biological properties. These properties can help guide cell behavior through the cell-matrix and cell-cell interactions established by cell binding motifs, mechanotransduction, diffusion of soluble factors and biodegradation.

For tissue regeneration, the one of the most important properties of an engineered scaffold is to present bioactive cues, such as cell-binding sequences or growth factors, to favor cell adhesion and proliferation. The modular nature of the ELR protein design and production offers an effective and crucially flexible approach for obtaining bioactive matrices with spatial and density control of different bioactivities. Moreover, this technological platform allows for independent modulation of the specific bioactive domains and mechanical properties. For example, bioactive motifs such as the integrinmediated adhesion peptide RGD derived from fibronectin ${ }^{[246]}$ have been incorporated into a bespoke ELR backbone to improve cell adhesion and spreading. Indeed, in this case, these cellular activities could be modulated as a function of RGD density in the molecular design. ${ }^{[180,247]}$

In consistency with this, Jeon and co-workers have investigated the effect of RGD domains within ELRs for the regeneration of different tissues. ${ }^{[248-251]}$ They used an RGD-ELR with a simple modular design in which RGD sequences were interspersed with tandem VPGVG repeats. An in vitro study with $\beta$-TC6 pancreatic cells showed that the presence of RGD enabled an effective communication with cells. ${ }^{[248]}$ The resulting RGD-ELR promoted the expression of E-cadherin and connexin-6 compared with the ELR control lacking the RGD domain. E-cadherin and connexin- 6 are cell-cell 
adhesion molecules involved in the regulation of islet association and in glucoseinduced insulin release, respectively. ${ }^{[252,253]}$ Moreover, the formation of spheroids with enhanced islet-like functions, such as insulin production or glucose sensitiveness, was observed, thus demonstrating efficient modulation of the cell behavior via integrinmediated signal transduction. In another study, coacervates of ELR embedding different cell types were engrafted in mice. The work exploited the thermoresponsiveness of the VPGVG domains to encapsulate pancreatic islets and adipose-derived stem cells (ADSC) so as to test their behavior in a mouse model. ${ }^{[249,250]}$ it was found that RGDELR matrices were able to maintain islet viability in vivo with notable activation of MAPK/p-Erk and PI3K/Akt/Foxo1/Pdx1 signaling pathways. ${ }^{[249]}$ These results were consistent with previous studies with adipose derived stem cells (ADSC). ${ }^{[250]}$ In this case, RGD-ELR hydrogel containing the ADSC developed to enhance tissue regeneration in a murine wound model in situ showed that RGD domains modulated ADSC response by upregulating survival pathways (Mek/Erk and PI3K/Akt). Additionally, it was also noted that the RGD-ELR scaffolds also promoted angiogenesis, with host endothelial cell recruitment and the formation of new vascularlike structures being observed in both in vivo studies.

The modular design of ELRs has also been exploited for the endowment of multiple functionalities into the same molecule. In order to control vascularization, Staubli et al. investigated the presence of bioactive domains in a chemically crosslinked ELR-based scaffolds. ${ }^{[254]}$ The authors embedded adipose tissue-derived stromal vascular fraction (SVF) cells in the crosslinked matrices and studied the effect of this bioactive scaffold on angiogenesis in vitro and in vivo. They observed that the bioactive scaffold, which contained the cell-binding domains (RGD), the endothelial specific cell binding domain (REDV) and an elastase-sensitive and cell-adhesion sequence (VGVAPG), had superior 
recruitment of host cells with improved infiltration of blood vessels in vivo. Indeed, the absence of bioactive domains was associated with no angiogenesis.

This multivalent modular design also allows the controlled incorporation of additional biofunctionalities. For example, growth factors can also be incorporated into the ELR backbone to develop tissue-specific scaffolds for regenerating complex tissues. In this regard, the vascular endothelial growth factor (VEGF) mimetic peptide QK (KLTWQELYQLKYKGI) was site-specifically tethered to ELR hydrogels through lysine side-groups was used to successfully promote and control angiogenesis. ${ }^{[255,256]}$ QK peptide retained its activity after bioconjugation, and endothelial cell proliferation could be controlled by varying the density of the growth factor in the ELR. ${ }^{[255]}$

In another study, multivalent ELR scaffolds were produced for bone repair and regeneration. ${ }^{[240]}$ The 3D hydrogel used in this case comprised two different ELRs: one that combined the VGVAPG with RGD domains and another that combined VGVAPG with osteinductive bone morphogenetic factor-2 (BMP-2). After recombinant production, both bioactive ELRs were mixed and chemically crosslinked into a hydrogel, and tested in vivo. Combination of the RGD domain with BMP-2 and the degradation motifs VGVAPG provided osteogenic and osteoinductive effects that promoted host cell integration and bone defect regeneration.

\subsection{Architecture and Stiffness Control}

In addition to biological signal transduction, mechanical behavior and scaffold architecture are also crucial parameters as regards the repair of tissue damage or controlling stem cell fate. Scaffold porosity and pore interconnectivity play an

important role in cell viability, proliferation, infiltration and ECM formation. ${ }^{[257]}$ In addition, the promotion of internal scaffold porosity is essential for the diffusion of 
nutrients, oxygen and other metabolites. ${ }^{[258]}$ Intrinsic parameters for ELR hydrogel manufacture, such as concentration or crosslinking degree, govern the intricate microarchitecture of the hydrogel. For example, the pore size and swelling ratio can be tuned by varying the hydrogel concentration. ${ }^{[217,241,259]}$

Physical and chemical techniques can also be applied to ELRs to control the macroscale architecture of the scaffold. In order to produce ELR-based microporous or fibrous scaffolds, salt leaching/gas foaming or electrospinning have been employed, respectively. Electrospinning of ELRs provides a reproducible methodology for the manufacture of 3D nanofibrous scaffolds with fiber morphology tunable at production. ${ }^{[260]}$ Electrospun ELR-based nanofiber matrices have been used to develop 3D scaffolds for several applications, which include dermal repair and as vascular grafts studies. ${ }^{[261-263]}$ Similarly, salt leaching coupled with gas foaming has been used to produce macroporous scaffolds based on crosslinked ELR hydrogels. ${ }^{[264,265]}$ This technique enables the pore size to be tuned on the microscale for optimal cell interaction as per requirement.

The viscoelastic properties of the natural ECM is another parameter of significance in the ECM-mediated control of cell behavior. ${ }^{[266]}$ As such, an ideal scaffold should have well defined stiffness modulation that recapitulates the mechanical behavior of targeted native ECM so as to provide desirable environment for each tissue. In this regard, the modular design and synthesis of ELRs, as well as crosslinking thereof allows for a higher degree of control of the stiffness of the resulting biomaterial. In line with this, ELR-based matrices have been designed to transduce biomechanical signals to Caco-2 cell monolayers in order to tune the organization of their actin skeleton and paracellular permeability. ${ }^{[267]}$ Modulation of RGD domains and the stiffness of the substrate independently affected cell spreading and cytoskeletal organization, thus demonstrating 
that intercellular junctions can be tuned by controlling biomechanical cell-matrix interactions.

In addition, there is increasing evidence that matrix stiffness strongly affects cell adhesion, proliferation, migration and differentiation, and even induces malignant phenotypes. ${ }^{[34,268,269]}$ In line with this, mesenchymal stem cells (MSCs), adult multipotent cells with excellent regenerative and immunomodulatory, have been shown to respond to mechanotransduction from the substrate and differentiate down specific lineages via an integrin-mediated mechanism. ${ }^{[270]}$ However, although MSCs are widely used in cell therapy for tissue regeneration, their behavior in $3 \mathrm{D}$ matrices is not yet entirely understood despite the fact that the control of cell fate is crucial for their therapeutic efficacy. To understand this, Heilshorn and coworkers investigated the role of matrix stiffness on human MSC (hMSC) differentiation using 3D macroporous ELR hydrogels. ${ }^{[271]}$ The ELR-based hydrogels incorporated two cell-binding domains (RGD and YIGSR) alternating with lysine residues intended for crosslinking. In this work, the varying concentration of the crosslinker was used to tune the stiffness of the hydrogel. After a 7 days in vitro incubation of hMSCs, no significant differences were observed between the two bioactive domain treatments. Although YIGSR domains enhance osteogenic differentiation in 2D studies, ligand presentation in $3 \mathrm{D}$ scaffold is greater than in $2 \mathrm{D}$, and consequently, the biological effect of the cell-binding domains varied significantly. However, increased matrix stiffness appeared to favor both osteogenic and adipogenic differentiation, possibly due to an increased cell-cell contact in the porous scaffold. These results demonstrate the importance of the 3D architecture, which strongly affects matrix-cell and cell-cell communication and, ultimately, stem cell fate.

\subsection{Cell-Stimulated Remodeling of ELR-based Scaffolds}


The essential aim of an ideal 3D scaffold for tissue repair is to attain complete regeneration of the damaged tissue with restoration of normal physiological function. This requires the secretion of renewed ECM by the host tissue cells and, consequently, the biodegradation and remodeling of the artificial scaffold. As such, matrix degradability is a key parameter in cell migration and scaffold infiltration. ${ }^{[272]}$

To attain this, recent studies in the development of ECM-mimicking scaffolds, ELRbased 3D-scaffolds designed to allow controlled scaffold remodeling in situ have been developed. ${ }^{[273-276]}$ Straley et al. bioproduced an ELR library based on a modular design containing different proteolytic sites in order to evaluate the degradation rate of the $3 \mathrm{D}$ networks after chemical crosslinking. ${ }^{[277]}$ Different degradation kinetics were observed depending on the epitope. Indeed, sensitivity to enzymatic degradation by tissue plasminogen activator (tPA) or urokinase plasminogen activator (uPA) was found to differ significantly. Similarly, Flora et al demonstrated that dynamic scaffolds can be developed by crosslinking ELRs with different degradation kinetics in order to successfully control spatial and temporally cell infiltration patterns. ${ }^{[273]}$

ELR-based hydrogel degradation and molecular architecture can also be modulated using synthetic crosslinkers with different functionalities. ${ }^{[274]}$ ELR network interconnectivity depends on the degree of functionalization with a crosslinker, as higher connectivity lowers the degradable fraction of the crosslinked material. As such, cell spreading can be controlled by using different crosslinking strategies to tune the internal hydrogel architecture and degradability.

Scaffold remodeling also seems to be crucial for controlling stem cell fate. It has been observed that the remodeling of a scaffold can affect the maintenance of neural progenitor cells (NPCs) with potential application in the structural repair of the brain or the spinal cord. ${ }^{[275]}$ However, to achieve this, it is necessary to generate a relevant 
number of stem cells and maintain their stemness. In this regard, 3D ELR-hydrogels have been successfully used to maintain and expand NPCs in high density cultures. ${ }^{\text {[275] }}$ In contrast to MSCs, hydrogel stiffness did not seem to affect NPC differentiation and stemness was found to depend strongly on whether (and how) the 3D matrix could be remodeled. In this study, the ELR design comprised of bioactive domains (cell-binding and proteolytic sites) alternating with tandems of elastin-like pentapeptides, which included lysine for subsequent crosslinking. By controlling the crosslinker density, the degradation of the scaffold could be controlled. Furthermore, by the introduction of proteolytic sites, cells were able to remodel the scaffold and cadherin-mediated cell-cell contact was increased, which enhanced NPC proliferation while maintaining the stemness phenotype. In another study evaluating NPC differentiation in remodelable ELR-scaffolds, it was observed that cell mediated degradation of the hydrogel is also necessary to enhance the differentiation of NPCs into astrocytes and neurons. ${ }^{[276]}$ In this work, NPCs encapsulated within ELR-scaffolds and chemically induced to differentiate showed that minimal cell-cell communication was required for NPCs to self-maintain metabolically active and enable correct differentiation. ${ }^{[276]}$ The fact that this only occurred when the scaffold was sufficiently degraded demonstrate that a dynamic response to cell-stimulated remodeling by the scaffold can be used for maintaining stemness at a high density and enable differentiation.

\subsection{Hybrid ELR-based Scaffolds}

In an effort to better mimic the complexity of the ECM, several approaches have been investigated for the creation of multifaceted scaffolds for tissue engineering involving combining ELRs with other ECM components or synthetic polymers. The incorporation of ELRs into the composite hydrogels can be used to improve the mechanical properties of the network as well as provide a broad range of bioactive cues that promote cell 
adhesion and proliferation. ${ }^{[278-283]}$ For instance, the combination of collagen with ELRs enables the production of biofunctional hydrogels with tunable mechanical properties for the regeneration of bone and soft tissues injuries, or for the manufacture of vascular grafts. ${ }^{[284-288]}$ Indeed, it has been demonstrated that the osteoinductive activity of collagen can be synergistically combined with the mechanical properties of the ELRs to biofabricate three-dimensional polymeric networks to guide tissue regeneration. ${ }^{\text {[288] }}$

ELRs have also been bioconjugated with structural polysaccharides such as hyaluronic acid (HA) for the regeneration of cartilage and fibrocartilage or chitosan for bone repair. ${ }^{[289-293]}$ While HA-containing hydrogels have been reported to promote the remodeling and deposition of the ECM, they lack elasticity and the bioactive quality associated with elastin presence in the ECM. This shortfall can be address by the addition of ELRs to these biomaterials. ${ }^{[290]}$ In addition, depending on the crosslinking strategy, this would not only improve the control of physical properties, such as shear thinning and self-healing, but also allow the endowment of particular bioactivity for bespoke biomedical application. ${ }^{[291-293]}$

Finally, other synthetic and biological molecules have been combined with ELRs in order to produce ELR-composites with improved properties. For example: the incorporation of fibronectin enhances the viability of stem cells,${ }^{[294]}$ polyethylene glycol enables the transparency of the ELR-based hydrogels to be improved; ${ }^{[295]}$ and the fabrication of injectable scaffolds for stem cells transplantation; ${ }^{[296]}$ peptide-based amphiphiles serve to guide supramolecular assembly in order to create self-assembled grafts for vascular applications; ${ }^{[280]}$ or textile components, such as polyvinylidene, provide suturability and long term stability to ELR-based vascular grafts. ${ }^{\text {[297] }}$ 


\section{Summary}

There is currently an increasing consensus among the biomaterials science community that the starting point for the successful repair of any tissue must be the development of scaffolds that are able to maintain a bi-directional communication with cells. The scaffold must mimic ECM-cell interactions that occur in the native tissue by providing a tissue-specific microenvironment (adequate microarchitecture, mechanical behavior and biochemical cues) in order to transduce and to interpret the signals to promote complete and functional regeneration of the damaged tissue.

In this sense, recombinant protein-based biomaterials represent a promising technological platform for the biofabrication of scaffolds for regenerative medicine with improved fidelity to normal ECM. Recombinant DNA technology is a powerful tool that allows the advantages of material science and biology to be combined to produce myriad protein products and guarantee an exhaustive control over the protein amino acid sequence, monodispersity and biofunctionality. Indeed, we can now synthesize ECM proteins with great complexity and specificity, such as tropoelastin, and polymeric constructs with modular designs that contain multiple biofunctionalities in a costeffective and scalable manner. Specifically, ELRs have been shown to combine the outstanding physicochemical and mechanical properties of tropoelastin, such as intrinsic disorder, reversible phase-transition behavior, extensibility, elastic recoil and resilience, within a simple polymeric structure. The simplicity and modularity of ELRs opens the door to a wide range of flexible molecular designs, which is difficult or impossible to achieve with complex proteins. In addition, the ability to control mechanical, biological and topographical parameters encourages their use in the development of dynamic, biocompatible and multivalent scaffolds for applications in regenerative medicine, while 
also allowing us to make progress in the effort to decipher the complex matrix-cell relationship that governs cell behavior and, ultimately, tissue regeneration.

\section{Acknowledgements}

The authors are grateful for funding from the European Commission (MSCA-ITN2014-ETN-642687, NMP-2014-646075), the Spanish Government (MAT2016-78903R, MAT2015-68901-R and RTI2018-096320-B-C22), the Junta de Castilla y León (VA317P18), Interreg V A España Portugal POCTEP (0624_2IQBIONEURO_6_E) and Centro en Red de Medicina Regenerativa y Terapia Celular de Castilla y León.

\section{Biographies}

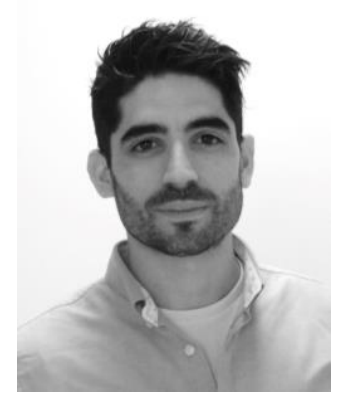

Sergio Acosta is undertaking his $\mathrm{PhD}$ in the Bioforge lab at the University of Valladolid. He obtained a M.S. in Molecular Nanoscience and Nanotechnology from the same University in 2015 and a B.A. in Biotechnology from the University of Leon in 2013. His research is on designing self-assembling biomaterials based on elastin-like recombinamers and antimicrobial peptides for nanomedicine. His main research interest is protein engineering and biofabrication of smart materials for biomedical applications. 


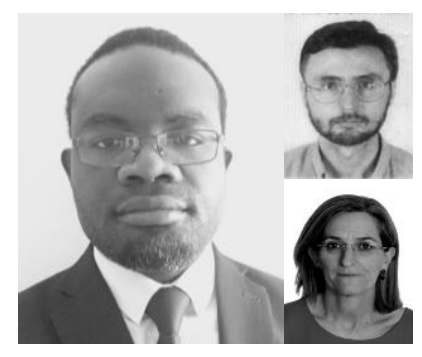

Lubinda Mbundi is a postdoctoral researcher at the University of Valladolid. He holds a $\mathrm{PhD}$ in Biomaterials and Tissue Regeneration from the University of Brighton. His main research interest is working at the interface of synthetic chemistry and biology, exploring the clinical efficacy of the biomaterials in wound healing, metabolic

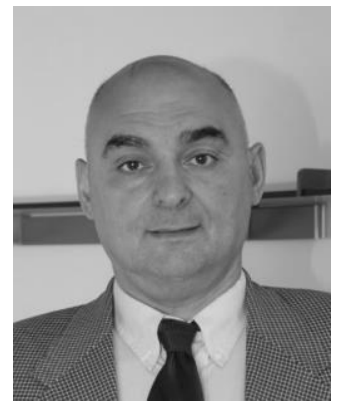

osteochondral diseases and decellularized organ-ECM matrices. Luis Quintanilla-Sierra received the Ph.D. degree in Sciences (Physics) in 1993. Since 2012, he is a senior researcher in the Bioforge Group. His research interests are the physical characterization of biomaterials. Virginia Reboto Rodríguez received the $\mathrm{PhD}$ in Sciences (Chemistry) in 2004. She is a senior researcher in the Bioforge Group of the University of Valladolid since 1999.

J. Carlos Rodríguez-Cabello is a Professor of Physics at the University of Valladolid. He is CEO and cofounder of the company Technical Proteins Nanobiotechnology SL. He is the director of the Bioforge Lab, a research group founded in 1996 and devoted to 
the development of Elastin-like materials in a pioneering effort on the use of genetic engineering and other biotechnologies for the creation of advanced materials. His interests move from studying basic knowledge on self-organization and the interplay between order and disorder in protein-like systems to applications of those materials in fields such as regenerative medicine, nanomedicine and nanotechnology. Complexity and multi(bio)functionality are the characteristics of the systems developed by his group. 


\section{References}

[1] M. B. Fisher, R. L. Mauck, Tissue Eng. - Part B Rev. 2013, 19, 1.

[2] B. V. Slaughter, S. S. Khurshid, O. Z. Fisher, A. Khademhosseini, N. A. Peppas, Adv. Mater. 2009, 21, 3307.

[3] M. P. Lutolf, J. A. Hubbell, Nat. Biotechnol. 2005, 23, 47.

[4] Y. Li, Y. Xiao, C. Liu, Chem. Rev. 2017, 117, 4376.

[5] L. Cai, S. C. Heilshorn, Acta Biomater. 2014, 10, 1751.

[6] S. Hinderer, S. L. Layland, K. Schenke-Layland, Adv. Drug Deliv. Rev. 2016, 97, 260.

[7] M. A. Karsdal, M. J. Nielsen, J. M. Sand, K. Henriksen, F. Genovese, A. C. Bay-Jensen, V. Smith, J. I. Adamkewicz, C. Christiansen, D. J. Leeming, Assay Drug Dev. Technol. 2013, 11, 70.

[8] R. Silva, B. Fabry, A. R. Boccaccini, Biomaterials 2014, 35, 6727.

[9] H. Knopf-Marques, M. Pravda, L. Wolfova, V. Velebny, P. Schaaf, N. E. Vrana, P. Lavalle, Adv. Healthc. Mater. 2016, 5, 2841.

[10] B. An, D. L. Kaplan, B. Brodsky, Front. Chem. 2014, 2.

[11] K. Cameron, R. Tan, W. Schmidt-Heck, G. Campos, M. J. Lyall, Y. Wang, B. Lucendo-Villarin, D. Szkolnicka, N. Bates, S. J. Kimber, J. G. Hengstler, P. Godoy, S. J. Forbes, D. C. Hay, Stem Cell Reports 2015, 5, 1250.

[12] L. Li, A. Mahara, Z. Tong, E. A. Levenson, C. L. Mcgann, X. Jia, T. Yamaoka, K. L. Kiick, Adv. Healthc. Mater. 2016, 5, 266.

[13] S. R. MacEwan, A. Chilkoti, Biopolymers 2010, 94, 60.

[14] G. L. Rosano, E. A. Ceccarelli, Front. Microbiol. 2014, 5.

[15] C. Frantz, K. M. Stewart, V. M. Weaver, J. Cell Sci. 2010, 123, 4195.

[16] T. J. McKee, G. Perlman, M. Morris, S. V. Komarova, Sci. Rep. 2019, 9 .

[17] F. M. Watt, H. Fujiwara, Cold Spring Harb. Perspect. Biol. 2011, 3, 1 .

[18] J. M. Aamodt, D. W. Grainger, Biomaterials 2016, 86, 68.

[19] B. Alberts, A. Johnson, J. Lewis, D. Morgan, M. Raff, K. Roberts, P. Walter, Molecular Biology of the Cell; 6th ed.; Garland Science, Taylor \& Francis Group, 2014. 
[20] L. Schaefer, R. M. Schaefer, Cell Tissue Res. 2010, 339, 237.

[21] R. V. Iozzo, L. Schaefer, Matrix Biol. 2015, 42, 11.

[22] R. K. W. Smith, A. E. Goodship, In Equine Exercise Physiology; Elsevier Ltd, 2008; pp. 106-131.

[23] R. K. W. Smith, In Diagnosis and Management of Lameness in the Horse: Second Edition; Ross, M. W.; Dyson, S. J., Eds.; Elsevier Inc., 2010; pp. 694-706.

[24] M. K. Gordon, R. A. Hahn, Cell Tissue Res. 2010, 339, 247.

[25] T. Rozario, D. W. DeSimone, Dev. Biol. 2010, 341, 126.

[26] J. Myllyharju, K. I. Kivirikko, Trends Genet. 2004, 20, 33.

[27] S. G. Wise, A. S. Weiss, Tropoelastin. Int. J. Biochem. Cell Biol. 2009, 41, 494-497.

[28] E. M. Green, J. C. Mansfield, J. S. Bell, C. P. Winlove, The structure and micromechanics of elastic tissue. Interface Focus 2014, 4.

[29] J. E. Wagenseil, R. P. Mecham, Birth Defects Res. Part C Embryo Today Rev. 2007, 81, 229.

[30] H. A. Lucero, H. M. Kagan, Cell. Mol. Life Sci. 2006, 63, 2304.

[31] S. D. Shapiro, S. K. Endicott, M. A. Province, J. A. Pierce, E. J. Campbell, J. Clin. Invest. 1991, 87, 1828.

[32] M. L. Smith, D. Gourdon, W. C. Little, K. E. Kubow, R. A. Eguiluz, S. Luna-Morris, V. Vogel, PLoS Biol. 2007, 5, e268.

[33] J. L. Young, A. W. Holle, J. P. Spatz, Exp. Cell Res. 2016, 343, 3.

[34] A. J. Engler, S. Sen, H. L. Sweeney, D. E. Discher, Cell 2006, 126, 677.

[35] P. N. T. Wells, H.-D. Liang, J. R. Soc. Interface 2011, 8, 1521.

[36] S. A. Guelcher, J. A. Sterling, Cancer Microenviron. 2011, 4, 247.

[37] M. Yoneda, M. Yoneda, H. Mawatari, K. Fujita, H. Endo, H. Iida, Y. Nozaki, K. Yonemitsu, T. Higurashi, H. Takahashi, N. Kobayashi, H. Kirikoshi, Y. Abe, M. Inamori, K. Kubota, S. Saito, M. Tamano, H. Hiraishi, S. Maeyama, N. Yamaguchi, S. Togo, A. Nakajima, Dig. Liver Dis. 2008, 40, 371.

[38] P. Martin, Science 1997, 276, 75.

[39] A. S. Craig, E. F. Eikenberry, D. A. D. Parry, Connect. Tissue Res. 1987, 16, 213. 
[40] S. Weiner, H. D. Wagner, Annu. Rev. Mater. Sci. 1998, 28, 271.

[41] D. H. Kim, E. A. Lipke, P. Kim, R. Cheong, S. Thompson, M. Delannoy, K. Y. Suh, L. Tung, A. Levchenko, Proc. Natl. Acad. Sci. U. S. A. 2010, 107, 565 .

[42] P. Fratzl, Curr. Opin. Colloid Interface Sci. 2003, 8, 32.

[43] M. C. Farach-Carson, R. C. Wagner, K. L. Kiick, In Tissue Engineering; Fisher, J. P.; Mikos, A. G.; Bronzina, J. D., Eds.; Taylor \& Francis Group, 2016; pp. 463-484.

[44] S. P. Massia, J. A. Hubbell, J. Cell Biol. 1991, 114, 1089.

[45] M. Arnold, E. A. Cavalcanti-Adam, R. Glass, J. Blümmel, W. Eck, M. Kantlehner, H. Kessler, J. P. Spatz, Chemphyschem 2004, 5, 383.

[46] J. M. Wallace, Q. Chen, M. Fang, B. Erickson, B. G. Orr, M. M. Banaszak Holl, Langmuir 2010, 26, 7349.

[47] T. Bage, T. Edymann, A. D. Metcalfe, B. Dheansa, L. Mbundi, Arch. Dermatol. Res. 2019, 311, 647.

[48] C. Kuschel, H. Steuer, A. N. Maurer, B. Kanzok, R. Stoop, B. Angres, Biotechniques 2006, 40, 523.

[49] H. Masuda, S. Ishihara, I. Harada, T. Mizutani, M. Ishikawa, K. Kawabata, H. Haga, Biotechniques 2014, 56.

[50] K. R. Johnson, J. L. Leight, V. M. Weaver, Methods Cell Biol. 2007, 83, 547.

[51] H. K. Kleinman, G. R. Martin, Semin. Cancer Biol. 2005, 15, 378.

[52] P. Macchiarini, P. Jungebluth, T. Go, M. A. Asnaghi, L. E. Rees, T. A. Cogan, A. Dodson, J. Martorell, S. Bellini, P. P. Parnigotto, S. C. Dickinson, A. P. Hollander, S. Mantero, M. T. Conconi, M. A. Birchall, Lancet 2008, 372, 2023.

[53] R. D. Ventura, A. R. Padalhin, C. M. Park, B. T. Lee, Mater. Sci. Eng. C 2019, 104.

[54] P. Lin, W. C. W. Chan, S. F. Badylak, S. N. Bhatia, Tissue Eng. 2004, 10, 1046.

[55] A. C. Oliveira, I. Garzón, A. M. Ionescu, V. Carriel, J. de la C. Cardona, M. González-Andrades, M. del M. Pérez, M. Alaminos, A. Campos, PLoS One 2013, 8, e66538.

[56] A. J. Sutherland, E. C. Beck, S. C. Dennis, G. L. Converse, R. A. Hopkins, C. J. Berkland, M. S. Detamore, PLoS One 2015, 10, 
e0121966.

[57] F. Rosso, G. Marino, A. Giordano, M. Barbarisi, D. Parmeggiani, A. Barbarisi, J. Cell. Physiol. 2005, 203, 465.

[58] S. F. Badylak, Biomaterials 2007, 28, 3587.

[59] Y. S. Kim, M. Majid, A. J. Melchiorri, A. G. Mikos, Bioeng. Transl. Med. 2019, 4, 83.

[60] M. A. Velasco, C. A. Narváez-Tovar, D. A. Garzón-Alvarado, Biomed Res. Int. 2015, 2015.

[61] C. E. Ayres, B. S. Jha, S. A. Sell, G. L. Bowlin, D. G. Simpson, Wiley Interdiscip. Rev. Nanomedicine Nanobiotechnology 2010, 2, 20.

[62] R. C. Dutta, A. K. Dutta, Biotechnol. Adv. 2009, 27, 334.

[63] K. Zhang, S. Wang, C. Zhou, L. Cheng, X. Gao, X. Xie, J. Sun, H. Wang, M. D. Weir, M. A. Reynolds, N. Zhang, Y. Bai, H. H. K. Xu, Bone Res. 2018, 6 .

[64] K. A. Kyburz, K. S. Anseth, Ann. Biomed. Eng. 2015, 43, 489.

[65] E. S. Place, N. D. Evans, M. M. Stevens, Nat. Mater. 2009, 8, 457.

[66] M. P. Lutolf, J. L. Lauer-Fields, H. G. Schmoekel, A. T. Metters, F. E. Weber, G. B. Fields, J. A. Hubbell, Proc. Natl. Acad. Sci. U. S. A. 2003, 100, 5413.

[67] J. E. Gagner, W. Kim, E. L. Chaikof, Acta Biomater. 2014, 10, 1542.

[68] T. B. Aigner, E. DeSimone, T. Scheibel, Adv. Mater. 2018, 30, 1704636.

[69] R. L. DiMarco, S. C. Heilshorn, Adv. Mater. 2012, 24, 3923.

[70] A. Sorushanova, L. M. Delgado, Z. Wu, N. Shologu, A. Kshirsagar, R. Raghunath, A. M. Mullen, Y. Bayon, A. Pandit, M. Raghunath, D. I. Zeugolis, Adv. Mater. 2019, 31 .

[71] D. L. Nettles, A. Chilkoti, L. A. Setton, Adv. Drug Deliv. Rev. 2010, $62,1479$.

[72] S. G. Wise, G. C. Yeo, M. A. Hiob, J. Rnjak-Kovacina, D. L. Kaplan, M. K. C. Ng, A. S. Weiss, Acta Biomater. 2014, 10, 1532.

[73] G. C. Yeo, A. S. Weiss, Proc. Natl. Acad. Sci. U. S. A. 2019, 116, 2042.

[74] J. F. Almine, S. G. Wise, A. S. Weiss, Birth Defects Res. Part C Embryo Today Rev. 2012, 96, 248. 
[75] S. M. Mithieux, A. S. Weiss, Adv. Protein Chem. 2005, 70, 437.

[76] S. G. Wise, A. S. Weiss, Int. J. Biochem. Cell Biol. 2009, 41, 494.

[77] S. M. Mithieux, S. G. Wise, A. S. Weiss, Adv. Drug Deliv. Rev. 2013, $65,421$.

[78] J. Gosline, M. Lillie, E. Carrington, P. Guerette, C. Ortlepp, K. Savage, Philos. Trans. R. Soc. B Biol. Sci. 2002, 357, 121.

[79] S. M. Mithieux, A. S. Weiss, Adv. Protein Chem. 2005, 70, 437.

[80] C. Baldock, A. F. Oberhauser, L. Ma, D. Lammie, V. Siegler, S. M. Mithieux, Y. Tu, J. Y. H. Chow, F. Suleman, M. Malfois, S. Rogers, L. Guo, T. C. Irving, T. J. Wess, A. S. Weiss, Proc. Natl. Acad. Sci. U. S. A. 2011, 108, 4322.

[81] A. Tarakanova, G. C. Yeo, C. Baldock, A. S. Weiss, M. J. Buehler, Macromol. Biosci. 2019, 19, 1800250.

[82] D. V Bax, U. R. Rodgers, M. M. M. Bilek, A. S. Weiss, J. Biol. Chem. 2009, 284, 28616.

[83] J. E. Wagenseil, R. P. Mecham, J. Cardiovasc. Transl. Res. 2012, 5, 264.

[84] L. D. Muiznieks, F. W. Keeley, Biochim. Biophys. Acta 2013, 1832, 866.

[85] H. Vindin, S. M. Mithieux, A. S. Weiss, Matrix Biol. 2019, 84, 4.

[86] H. Piontkivska, Y. Zhang, E. D. Green, L. Elnitski, BMC Genomics 2004, 5,31 .

[87] G. C. Yeo, C. Baldock, S. G. Wise, A. S. Weiss, ACS Biomater. Sci. Eng. 2017, 3, 2832.

[88] G. C. Yeo, A. Tarakanova, C. Baldock, S. G. Wise, M. J. Buehler, A. S. Weiss, Sci. Adv. 2016, 2, e1501145.

[89] A. Tarakanova, G. C. Yeo, C. Baldock, A. S. Weiss, M. J. Buehler, Proc. Natl. Acad. Sci. U. S. A. 2018, 115, 7338.

[90] G. C. Yeo, C. Baldock, A. Tuukkanen, M. Roessle, L. B. Dyksterhuis, S. G. Wise, J. Matthews, S. M. Mithieux, A. S. Weiss, Proc. Natl. Acad. Sci. U. S. A. 2012, 109, 2878.

[91] G. C. Yeo, F. W. Keeley, A. S. Weiss, Adv. Colloid Interface Sci. 2011, 167, 94.

[92] Y. Tu, S. G. Wise, A. S. Weiss, Micron 2010, 41, 268. 
[93] J. Thomson, M. Singh, A. Eckersley, S. A. Cain, M. J. Sherratt, C. Baldock, Semin. Cell Dev. Biol. 2019, 89, 109.

[94] R. Wang, J. Ozsvar, G. C. Yeo, A. S. Weiss, Hierarchical assembly of elastin materials. Curr. Opin. Chem. Eng. 2019, 24, 54-60.

[95] J. M. Gluck, A. W. Herren, S. Yechikov, H. K. J. Kao, A. Khan, B. S. Phinney, N. Chiamvimonvat, J. W. Chan, D. K. Lieu, PLoS One 2017, 12 , e0185125.

[96] J. Holst, S. Watson, M. S. Lord, S. S. Eamegdool, D. V Bax, L. B. Nivison-Smith, A. Kondyurin, L. Ma, A. F. Oberhauser, A. S. Weiss, J. E. J. Rasko, Nat. Biotechnol. 2010, 28, 1123.

[97] N. Annabi, S. M. Mithieux, A. S. Weiss, F. Dehghani, Biomaterials 2010, 31, 1655.

[98] S. M. Mithieux, S. G. Wise, M. J. Raftery, B. Starcher, A. S. Weiss, J. Struct. Biol. 2005, 149, 282.

[99] X. Hu, S. H. Park, E. S. Gil, X. X. Xia, A. S. Weiss, D. L. Kaplan, Biomaterials 2011, 32, 8979.

[100] D. E. Discher, P. Janmey, Y. L. Wang, Science (80-. ). 2005, 310, 1139.

[101] A. Zemel, F. Rehfeldt, A. E. X. Brown, D. E. Discher, S. A. Safran, Nat. Phys. 2010, 6, 468.

[102] A. Hinek, M. Rabinovitch, J. Cell Biol. 1994, 126, 563.

[103] P. Lee, G. C. Yeo, A. S. Weiss, FEBS J. 2017, 284, 2216.

[104] J. Bella, M. Eaton, B. Brodsky, H. M. Berman, Science 1994, 266, 75.

[105] S. Rauscher, R. Pomès, Adv. Exp. Med. Biol. 2012, 725, 159.

[106] L. D. Muiznieks, A. S. Weiss, F. W. Keeley, Biochem. Cell Biol. 2010, 88, 239.

[107] P. Tompa, Bioessays 2003, 25, 847.

[108] L. D. Muiznieks, A. S. Weiss, Biochemistry 2007, 46, 8196.

[109] L. D. Muiznieks, A. S. Weiss, F. W. Keeley, Biochem. Cell Biol. 2010, 88, 239.

[110] S. Rauscher, R. Pomès, Elife 2017, 6.

[111] P. Romero, Z. Obradovic, X. Li, E. C. Garner, C. J. Brown, A. K. Dunker, Proteins Struct. Funct. Genet. 2001, 42, 38. 
[112] S. Rauscher, S. Baud, M. Miao, F. W. Keeley, R. Pomès, Structure 2006, 14, 1667.

[113] M. Miao, C. M. Bellingham, R. J. Stahl, E. E. Sitarz, C. J. Lane, F. W. Keeley, J. Biol. Chem. 2003, 278, 48553.

[114] A. S. Tatham, P. R. Shewry, Trends Biochem. Sci. 2000, 25, 567.

[115] B. Vrhovski, A. S. Weiss, Eur. J. Biochem. 1998, 258, 1.

[116] C. A. J. Hoeve, P. J. Flory, Biopolymers 1974, 13, 677.

[117] D. W. Urry, T. Hugel, M. Seitz, H. E. Gaub, L. Sheiba, J. Dea, J. Xu, T. Parker, Philos. Trans. R. Soc. B Biol. Sci. 2002, 357, 169.

[118] T. Weis-Fogh, S. O. Andersen, Nature 1970, 227, 718.

[119] W. R. Gray, L. B. Sandberg, J. A. Foster, Nature 1973, 246, 461.

[120] D. W. Urry, W. D. Cunningham, T. Ohnishi, Biochemistry 1974, 13, 609.

[121] A. M. Tamburro, V. Guantieri, A. Scopa, J. M. Drabble, Chirality $1991,3,318$.

[122] B. Prescott, V. Renugopalakrishnan, G. J. Thomas Jr., Bioploymers 1987, 26, 934.

[123] A. M. Tamburro, B. Bochicchio, A. Pepe, Biochemistry 2003, 42, 13347.

[124] L. B. Dyksterhuis, E. A. Carter, S. M. Mithieux, A. S. Weiss, Arch. Biochem. Biophys. 2009, 487, 79.

[125] J. L. Balestrini, A. L. Gard, K. A. Gerhold, E. C. Wilcox, A. Liu, J. Schwan, A. V Le, P. Baevova, S. Dimitrievska, L. Zhao, S.

Sundaram, H. Sun, L. Rittié, R. Dyal, T. J. Broekelmann, R. P. Mecham, M. A. Schwartz, L. E. Niklason, E. S. White, Biomaterials 2016, 102, 220.

[126] L. Dew, W. R. English, C. K. Chong, S. MacNeil, Tissue Eng. Part A 2016, 22, 1317.

[127] Z. I. Foraida, T. Kamaldinov, D. A. Nelson, M. Larsen, J.

Castracane, Acta Biomater. 2017, 62, 116.

[128] D. V Bax, D. R. McKenzie, M. M. M. Bilek, A. S. Weiss, Biomaterials 2011, 32, 6710.

[129] B. Aghaei-Ghareh-Bolagh, J. Guan, Y. Wang, A. D. Martin, R.

Dawson, S. M. Mithieux, A. S. Weiss, Biomaterials 2019, 188, 50. 
[130] D. V. Bax, Y. Wang, Z. Li, P. K. M. Maitz, D. R. McKenzie, M. M. M. Bilek, A. S. Weiss, Biomaterials 2011, 32, 5100.

[131] G. C. Yeo, A. Kondyurin, E. Kosobrodova, A. S. Weiss, M. M. M. Bilek, J. R. Soc. Interface 2017, 14, 20160837.

[132] I. Kondyurina, S. G. Wise, A. K. Y. Ngo, E. C. Filipe, A. Kondyurin, A. S. Weiss, S. Bao, M. M. M. Bilek, Biomed. Mater. 2017, 12, 045002.

[133] T. Sugiura, R. Agarwal, S. Tara, T. Yi, Y.-U. Lee, C. K. Breuer, A. S. Weiss, T. Shinoka, Acta Biomater. 2017, 52, 74.

[134] S. Landau, A. A. Szklanny, G. C. Yeo, Y. Shandalov, E. Kosobrodova, A. S. Weiss, S. Levenberg, Biomaterials 2017, 122, 72.

[135] S. Ito, S. Ishimaru, S. E. Wilson, Angiology 1998, 49, 289.

[136] S. J. Lee, J. J. Yoo, G. J. Lim, A. Atala, J. Stitzel, J. Biomed. Mater. Res. - Part A 2007, 83, 999.

[137] L. Nivison-Smith, J. Rnjak, A. S. Weiss, Acta Biomater. 2010, 6, 354.

[138] Y. Yin, S. G. Wise, N. J. Nosworthy, A. Waterhouse, D. V Bax, H. Youssef, M. J. Byrom, M. M. M. Bilek, D. R. McKenzie, A. S.

Weiss, M. K. C. Ng, Biomaterials 2009, 30, 1675.

[139] D. V. Bax, A. Kondyurin, A. Waterhouse, D. R. McKenzie, A. S. Weiss, M. M. M. Bilek, Biomaterials 2014, 35, 6797.

[140] S. G. Wise, M. J. Byrom, A. Waterhouse, P. G. Bannon, M. K. C. $\mathrm{Ng}$, A. S. Weiss, Acta Biomater. 2011, 7, 295.

[141] R. Wang, J. Ozsvar, B. Aghaei-Ghareh-Bolagh, M. A. Hiob, S. M. Mithieux, A. S. Weiss, Biomaterials 2019, 192, 334.

[142] B. D. Wilson, C. C. Gibson, L. K. Sorensen, M. Y. Guilhermier, M. Clinger, L. L. Kelley, Y. T. E. Shiu, D. Y. Li, Ann. Biomed. Eng. 2011, 39, 337.

[143] M. M. M. Bilek, D. V. Bax, A. Kondyurin, Y. Yin, N. J. Nosworthy, K. Fisher, A. Waterhouse, A. S. Weiss, C. G. Dos Remedios, D. R. McKenzie, Proc. Natl. Acad. Sci. U. S. A. 2011, 108, 14405.

[144] S. Wise, M. Santos, P. Michael, B. Lee, J. Hung, A. Weiss, M. Bilek, M. Ng, Hear. Lung Circ. 2017, 26, S197.

[145] Y. Wang, J. Beekman, J. Hew, S. Jackson, A. C. Issler-Fisher, R. Parungao, S. S. Lajevardi, Z. Li, P. K. M. Maitz, Adv. Drug Deliv. 
Rev. 2018, 123, 3.

[146] M. Xue, C. J. Jackson, Adv. Wound Care 2015, 4, 119.

[147] M. McKenzie, D. Betts, A. Suh, K. Bui, L. Kim, H. Cho, Molecules 2015, 20, 20397.

[148] S. M. Mithieux, J. E. J. Rasko, A. S. Weiss, Biomaterials 2004, 25, 4921.

[149] J. Rnjak-Kovacina, S. G. Wise, Z. Li, P. K. M. Maitz, C. J. Young, Y. Wang, A. S. Weiss, Biomaterials 2011, 32, 6729.

[150] J. C. Rodríguez-Cabello, I. González de Torre, A. Ibañez-Fonseca, M. Alonso, Adv. Drug Deliv. Rev. 2018, 129, 118.

[151] Y. Wang, S. M. Mithieux, Y. Kong, X.-Q. Wang, C. Chong, A. Fathi, F. Dehghani, E. Panas, J. Kemnitzer, R. Daniels, R. M. Kimble, P. K. Maitz, Z. Li, A. S. Weiss, Adv. Healthc. Mater. 2015, 4, 576.

[152] J. Rnjak, S. G. Wise, S. M. Mithieux, A. S. Weiss, Tissue Eng. Part B Rev. 2011, 17, 81.

[153] S. M. Mithieux, A. S. Weiss, Acta Biomater. 2017, 52, 33.

[154] N. Annabi, D. Rana, E. Shirzaei Sani, R. Portillo-Lara, J. L. Gifford, M. M. Fares, S. M. Mithieux, A. S. Weiss, Biomaterials 2017, 139, 229.

[155] K. Yue, X. Li, K. Schrobback, A. Sheikhi, N. Annabi, J. Leijten, W. Zhang, Y. S. Zhang, D. W. Hutmacher, T. J. Klein, A.

Khademhosseini, Biomaterials 2017, 139, 163.

[156] S. M. Mithieux, B. Aghaei-Ghareh-Bolagh, L. Yan, K. V Kuppan, Y. Wang, F. Garces-Suarez, Z. Li, P. K. Maitz, E. A. Carter, C.

Limantoro, W. Chrzanowski, D. Cookson, A. Riboldi-Tunnicliffe, C. Baldock, K. Ohgo, K. K. Kumashiro, G. Edwards, A. S. Weiss, Adv. Healthc. Mater. 2018, 7, e1701206.

[157] G. C. Yeo, E. Kosobrodova, A. Kondyurin, D. R. McKenzie, M. M. Bilek, A. S. Weiss, Macromol. Biosci. 2019, 19, e1800233.

[158] J. D. White, S. Wang, A. S. Weiss, D. L. Kaplan, Acta Biomater. 2015, 14,1 .

[159] R. Calabrese, N. Raia, W. Huang, C. E. Ghezzi, M. Simon, C. Staii, A. S. Weiss, D. L. Kaplan, J. Tissue Eng. Regen. Med. 2017, 11, 2549.

[160] N. Annabi, Y. N. Zhang, A. Assmann, E. S. Sani, G. Cheng, A. D. Lassaletta, A. Vegh, B. Dehghani, G. U. Ruiz-Esparza, X. Wang, S. 
Gangadharan, A. S. Weiss, A. Khademhosseini, Sci. Transl. Med. 2017, 9, eaai7466.

[161] J. R. Soucy, E. Shirzaei Sani, R. Portillo Lara, D. Diaz, F. Dias, A. S. Weiss, A. N. Koppes, R. A. Koppes, N. Annabi, Tissue Eng. Part A 2018, 24, 1393.

[162] N. Annabi, S. R. Shin, A. Tamayol, M. Miscuglio, M. A. Bakooshli, A. Assmann, P. Mostafalu, J.-Y. Sun, S. Mithieux, L. Cheung, X. S. Tang, A. S. Weiss, A. Khademhosseini, Adv. Mater. 2016, $28,40$.

[163] T. Pesqueira, R. Costa-Almeida, S. M. Mithieux, P. S. Babo, A. R. Franco, B. B. Mendes, R. M. A. Domingues, P. Freitas, R. L. Reis, M. E. Gomes, A. S. Weiss, J. Mater. Chem. B 2018, 6, 1066.

[164] L. J. Santos, R. L. Reis, M. E. Gomes, Trends Biotechnol. 2015, 33, 471.

[165] H.-M. Yun, S.-J. Ahn, K.-R. Park, M.-J. Kim, J.-J. Kim, G.-Z. Jin, H.-W. Kim, E.-C. Kim, Biomaterials 2016, 85, 88.

[166] C. A. Cezar, E. T. Roche, H. H. Vandenburgh, G. N. Duda, C. J. Walsh, D. J. Mooney, Proc. Natl. Acad. Sci. U. S. A. 2016, 113, 1534.

[167] J. Meng, B. Xiao, Y. Zhang, J. Liu, H. Xue, J. Lei, H. Kong, Y. Huang, Z. Jin, N. Gu, H. Xu, Sci. Rep. 2013, 3, 2655.

[168] D. W. Urry, Methods Enzymol. 1982, 82, 673.

[169] J. A. Foster, E. Bruenger, W. R. Gray, L. B. Sandberg, J. Biol. Chem. 1973, 248, 2876.

[170] C. M. Bellingham, M. A. Lillie, J. M. Gosline, G. M. Wright, B. C. Starcher, A. J. Bailey, K. A. Woodhouse, F. W. Keeley, Biopolymers 2003, 70, 445 .

[171] T. Tamura, T. Yamaoka, S. Kunugi, A. Panitch, D. A. Tirrell, Biomacromolecules 2000, 1, 552.

[172] D. W. Urry, J. Phys. Chem. B 1997, 101, 11007.

[173] W. Kim, E. L. Chaikof, Adv. Drug Deliv. Rev. 2010, 62, 1468.

[174] E. R. Wright, R. A. McMillan, A. Cooper, R. P. Apkarian, V. P. Conticello, Adv. Funct. Mater. 2002, 12, 149.

[175] K. Nagapudi, W. T. Brinkman, J. Leisen, B. S. Thomas, E. R. Wright, C. Haller, X. Wu, R. P. Apkarian, V. P. Conticello, E. L. Chaikof, Macromolecules 2005, 38, 345.

[176] G. P. Richman, D. A. Tirrell, A. R. Asthagiri, J. Control. Release 
2005, 101, 3 .

[177] A. Panitch, T. Yamaoka, M. J. Fournier, T. L. Mason, D. A. Tirrell, Macromolecules 1999, 32, 1701.

[178] S. C. Heilshorn, K. A. DiZio, E. R. Welsh, D. A. Tirrell, Biomaterials 2003, 24, 4245.

[179] E. R. Welsh, D. A. Tirrell, Biomacromolecules 2000, 1, 23.

[180] J. C. Liu, D. A. Tirrell, Biomacromolecules 2008, 9, 2984.

[181] S. R. MacEwan, A. Chilkoti, Biopolymers 2010, 94, 60.

[182] K. P. McGrath, D. A. Tirrell, M. Kawai, T. L. Mason, M. J. Fournier, Biotechnol. Prog. 1990, 6, 188.

[183] D. Mozhdehi, K. M. Luginbuhl, S. Roberts, A. Chilkoti, In Sequence-Controlled Polymers; Lutz, J., Ed.; Wiley-VCH Verlag GmbH \& Co. KGaA: Weinheim, Germany, 2017; pp. 91-115.

[184] J. R. McDaniel, J. A. MacKay, F. G. Quiroz, A. Chilkoti, Biomacromolecules 2010, 11, 944.

[185] M. Amiram, F. G. Quiroz, D. J. Callahan, A. Chilkoti, Nat. Mater. 2011, 10, 141.

[186] M. Kim, C. Elvin, A. Brownlee, R. Lyons, Protein Expr. Purif. 2007, $52,230$.

[187] Y. Pang, J. Liu, Y. Qi, X. Li, A. Chilkoti, Angew. Chemie Int. Ed. 2016, 55, 10296.

[188] M. Barroca, P. Rodrigues, R. Sobral, M. M. R. Costa, S. R. Chaves, R. MacHado, M. Casal, T. Collins, Sci. Rep. 2016, 6.

[189] A. M. Edlund, J. Jones, R. Lewis, J. C. Quinn, N. Biotechnol. 2018, $42,12$.

[190] M. W. T. Werten, G. Eggink, M. A. Cohen Stuart, F. A. de Wolf, Biotechnol. Adv. 2019, 37, 642.

[191] R. W. Herzog, N. K. Singh, D. W. Urry, H. Daniell, Appl. Microbiol. Biotechnol. 1997, 47, 368.

[192] A. J. Conley, J. J. Joensuu, A. M. Jevnikar, R. Menassa, J. E. Brandle, Biotechnol. Bioeng. 2009, 103, 562.

[193] J. Yin, G. Li, X. Ren, G. Herrler, J. Biotechnol. 2007, 127, 335.

[194] D. E. Meyer, A. Chilkoti, Nat. Biotechnol. 1999, 17, 1112.

[195] E. R. Wright, V. P. Conticello, Adv. Drug Deliv. Rev. 2002, 54, 
1057.

[196] M. Dzuricky, S. Roberts, A. Chilkoti, Biochemistry 2018, 57, 2405.

[197] A. Fernández-Colino, F. J. Arias, M. Alonso, J. C. RodríguezCabello, Biomacromolecules 2015, 16, 3389.

[198] M. Dai, J. Haghpanah, N. Singh, E. W. Roth, A. Liang, R. S. Tu, J. K. Montclare, Biomacromolecules 2011, 12, 4240.

[199] A. J. Olsen, P. Katyal, J. S. Haghpanah, M. B. Kubilius, R. Li, N. L. Schnabel, S. C. O’Neill, Y. Wang, M. Dai, N. Singh, R. S. Tu, J. K. Montclare, Biomacromolecules 2018, 19, 1552.

[200] A. Fernández-Colino, F. J. Arias, M. Alonso, J. Carlos RodríguezCabello, Biomacromolecules 2014, 15, 3781.

[201] W. Huang, A. Rollett, D. L. Kaplan, Expert Opin. Drug Deliv. 2015, 12,779 .

[202] A. Poursaid, R. Price, A. Tiede, E. Olson, E. Huo, L. McGill, H. Ghandehari, J. Cappello, Biomaterials 2015, 57, 142.

[203] E. G. Roberts, N. Rim, W. Huang, A. Tarakanova, J. Yeo, M. J. Buehler, D. L. Kaplan, J. Y. Wong, Macromol. Biosci. 2018, 18, 1800265.

[204] I. Weitzhandler, M. Dzuricky, I. Hoffmann, F. Garcia Quiroz, M. Gradzielski, A. Chilkoti, Biomacromolecules 2017, 18, 2419.

[205] S. Salinas-Fernández, M. Santos, M. Alonso, L. Quintanilla, J. C. Rodríguez-Cabello, Appl. Mater. Today.

[206] W. M. Park, J. A. Champion, J. Am. Chem. Soc. 2014, 136, 17906.

[207] S. Roberts, T. S. Harmon, J. L. Schaal, V. Miao, K. Li, A. Hunt, Y. Wen, T. G. Oas, J. H. Collier, R. V. Pappu, A. Chilkoti, Nat. Mater. 2018, $17,1154$.

[208] J. R. McDaniel, I. Weitzhandler, S. Prevost, K. B. Vargo, M. S. Appavou, D. A. Hammer, M. Gradzielski, A. Chilkoti, Nano Lett. 2014, 14, 6590 .

[209] J. L. Schaal, X. Li, E. Mastria, J. Bhattacharyya, M. R. Zalutsky, A. Chilkoti, W. Liu, J. Control. Release 2016, 228, 58.

[210] M. B. van Eldijk, J. C.-Y. Wang, I. J. Minten, C. Li, A. Zlotnick, R. J. M. Nolte, J. J. L. M. Cornelissen, J. C. M. van Hest, J. Am. Chem. Soc. 2012, 134, 18506.

[211] D. H. T. Le, Y. Tsutsui, A. Sugawara-Narutaki, H. Yukawa, Y. 
Baba, C. Ohtsuki, J. Biomed. Mater. Res. Part A 2017, 105, 2475.

[212] C. M. Madl, S. C. Heilshorn, H. M. Blau, Nature 2018, 557, 335.

[213] S. Elsharkawy, M. Al-Jawad, M. F. Pantano, E. Tejeda-Montes, K. Mehta, H. Jamal, S. Agarwal, K. Shuturminska, A. Rice, N. V. Tarakina, R. M. Wilson, A. J. Bushby, M. Alonso, J. C. RodriguezCabello, E. Barbieri, A. del Río Hernández, M. M. Stevens, N. M. Pugno, P. Anderson, A. Mata, Nat. Commun. 2018, 9, 2145.

[214] Y. Li, J. C. Rodriguez-Cabello, C. Aparicio, ACS Appl. Mater. Interfaces 2017, 9, 5838.

[215] O. Gourgas, L. D. Muiznieks, D. G. Bello, A. Nanci, S. Sharpe, M. Cerruti, Biomacromolecules 2019, 20, 2625.

[216] M. K. McHale, L. A. Setton, A. Chilkoti, Tissue Eng. 2005, 11, 1768.

[217] I. González De Torre, M. Santos, L. Quintanilla, A. Testera, M. Alonso, J. C. Rodríguez Cabello, Acta Biomater. 2014, 10, 2495.

[218] M. S. Desai, E. Wang, K. Joyner, T. W. Chung, H.-E. Jin, S.-W. Lee, Biomacromolecules 2016, 17, 2409.

[219] P. L. Benitez, J. A. Sweet, H. Fink, K. P. Chennazhi, S. V. Nair, A. Enejder, S. C. Heilshorn, Adv. Healthc. Mater. 2013, 2, 114.

[220] P. J. Nowatzki, D. A. Tirrell, Biomaterials 2004, 25, 1261.

[221] D. W. Lim, D. L. Nettles, L. A. Setton, A. Chilkoti, Biomacromolecules 2007, 8, 1463.

[222] K. Di Zio, D. A. Tirrell, Macromolecules 2003, 36, 1553.

[223] K. Nagapudi, W. T. Brinkman, J. E. Leisen, L. Huang, R. A. McMillan, R. P. Apkarian, V. P. Conticello, E. L. Chaikof, Macromolecules 2002, 35, 1730.

[224] J. Raphel, A. Parisi-Amon, S. C. Heilshorn, J. Mater. Chem. 2012, 22, 19429.

[225] C. M. Madl, L. M. Katz, S. C. Heilshorn, Adv. Funct. Mater. 2016, 26,3612 .

[226] U. M. Krishna, A. W. Martinez, J. M. Caves, E. L. Chaikof, Acta Biomater. 2012, 8, 988.

[227] C. M. Madl, S. C. Heilshorn, Bioconjug. Chem. 2017, 28, 724.

[228] M. J. Brennan, B. F. Kilbride, J. J. Wilker, J. C. Liu, Biomaterials 2017, 124, 116. 
[229] R. Petitdemange, E. Garanger, L. Bataille, K. Bathany, B. Garbay, T. J. Deming, S. Lecommandoux, Bioconjug. Chem. 2017, 28, 1403.

[230] D. Asai, D. Xu, W. Liu, F. Garcia Quiroz, D. J. Callahan, M. R. Zalutsky, S. L. Craig, A. Chilkoti, Biomaterials 2012, 33, 5451.

[231] D. Asai, T. Kanamoto, M. Takenaga, H. Nakashima, Acta Biomater. 2017, 64, 116.

[232] Y.-N. Zhang, R. K. Avery, Q. Vallmajo-Martin, A. Assmann, A. Vegh, A. Memic, B. D. Olsen, N. Annabi, A. Khademhosseini, $A d v$. Funct. Mater. 2015, 25, 4814.

[233] M. A. Gonzalez, J. R. Simon, A. Ghoorchian, Z. Scholl, S. Lin, M. Rubinstein, P. Marszalek, A. Chilkoti, G. P. López, X. Zhao, Adv. Mater. 2017, 29, 1604743.

[234] D. T. Ta, R. Vanella, M. A. Nash, ACS Appl. Mater. Interfaces 2018, $10,30147$.

[235] S. A. Costa, J. R. Simon, M. Amiram, L. Tang, S. Zauscher, E. M. Brustad, F. J. Isaacs, A. Chilkoti, Adv. Mater. 2018, 30, 1704878.

[236] Y. Kambe, T. Tokushige, A. Mahara, Y. Iwasaki, T. Yamaoka, Polym. J. 2019, 51, 97.

[237] C. Chung, B. L. Pruitt, S. C. Heilshorn, Biomater. Sci. 2013, 1, 1082.

[238] C. Chung, K. J. Lampe, S. C. Heilshorn, Biomacromolecules 2012 , $13,3912$.

[239] H. Wang, A. Paul, D. Nguyen, A. Enejder, S. C. Heilshorn, ACS Appl. Mater. Interfaces 2018, 10, 21808.

[240] D. J. Coletta, A. Ibáñez-Fonseca, L. R. Missana, M. V Jammal, E. J. Vitelli, M. Aimone, F. Zabalza, J. P. M. Issa, M. Alonso, J. C. Rodríguez-Cabello, S. Feldman, Tissue Eng. Part A 2017, 23, 1361.

[241] Y.-N. Zhang, R. K. Avery, Q. Vallmajo-Martin, A. Assmann, A. Vegh, A. Memic, B. D. Olsen, N. Annabi, A. Khademhosseini, $A d v$. Funct. Mater. 2015, 25, 4814.

[242] F. Sun, W. Bin Zhang, A. Mahdavi, F. H. Arnold, D. A. Tirrell, Proc. Natl. Acad. Sci. U. S. A. 2014, 111, 11269.

[243] F. J. O’Brien, B. A. Harley, I. V. Yannas, L. J. Gibson, Biomaterials 2005, 26, 433.

[244] S. R. Peyton, A. J. Putnam, J. Cell. Physiol. 2005, 204, 198.

[245] S. Khetan, M. Guvendiren, W. R. Legant, D. M. Cohen, C. S. Chen, 
J. A. Burdick, Nat. Mater. 2013, 12, 458.

[246] E. Ruoslahti, Annu. Rev. Cell Dev. Biol. 1996, 12, 697.

[247] A. Nicol, D. Channe Gowda, D. W. Urry, J. Biomed. Mater. Res. 1992, 26, 393.

[248] K.-M. Lee, G.-S. Jung, J.-K. Park, S.-K. Choi, W. B. Jeon, Acta Biomater. 2013, 9, 5600.

[249] K.-M. Lee, J.-H. Kim, E.-S. Choi, E. Kim, S.-K. Choi, W. B. Jeon, Acta Biomater. 2019, 94, 351.

[250] S. K. Choi, J. K. Park, J. H. Kim, K. M. Lee, E. Kim, K. S. Jeong, W. B. Jeon, J. Control. Release 2016, 237, 89.

[251] J. Park, J. Y. Kim, S.-K. Choi, J. Y. Kim, J. H. Kim, W. B. Jeon, J. E. Lee, Nanomedicine Nanotechnology, Biol. Med. 2017, 13, 1853.

[252] A. C. Hauge-Evans, P. E. Squires, S. J. Persaud, P. M. Jones, Diabetes 1999, 48, 1402.

[253] S. Le Gurun, D. Martin, A. Formenton, P. Maechler, D. Caille, G. Waeber, P. Meda, J.-A. Haefliger, J. Biol. Chem. 2003, 278, 37690.

[254] S. M. Staubli, G. Cerino, I. Gonzalez De Torre, M. Alonso, D. Oertli, F. Eckstein, K. Glatz, J. C. Rodríguez Cabello, A. Marsano, Biomaterials 2017, 135, 30.

[255] L. Cai, C. B. Dinh, S. C. Heilshorn, Biomater. Sci. 2014, 2, 757.

[256] T. Flora, I. G. de Torre, M. Alonso, J. C. Rodríguez-Cabello, J. Mater. Sci. Mater. Med. 2019, 30, 30.

[257] N. Annabi, J. W. Nichol, X. Zhong, C. Ji, S. Koshy, A. Khademhosseini, F. Dehghani, Tissue Eng. Part B. Rev. 2010, 16, 371.

[258] Q. L. Loh, C. Choong, Tissue Eng. Part B. Rev. 2013, 19, 485.

[259] D. W. Lim, D. L. Nettles, L. A. Setton, A. Chilkoti, Biomacromolecules 2008, 9, 222.

[260] L. Huang, R. A. McMillan, R. P. Apkarian, B. Pourdeyhimi, V. P. Conticello, E. L. Chaikof, Macromolecules 2000, 33, 2989.

[261] M. Putzu, F. Causa, V. Nele, I. G. de Torre, J. C. Rodriguez-Cabello, P. A. Netti, Biofabrication 2016, 8, 045009.

[262] I. González de Torre, A. Ibáñez-Fonseca, L. Quintanilla, M. Alonso, J.-C. Rodríguez-Cabello, Acta Biomater. 2018, 72, 137. 
[263] A. Fernández- Colino, F. Wolf, S. Rütten, J. C. Rodríguez- Cabello, S. Jockenhoevel, P. Mela, Macromol. Biosci. 2018, 18, 1800147.

[264] L. Martín, M. Alonso, A. Girotti, F. J. Arias, J. C. RodríguezCabello, Biomacromolecules 2009, 10, 3015.

[265] A. Fernández-Colino, F. Wolf, H. Keijdener, S. Rütten, T. SchmitzRode, S. Jockenhoevel, J. C. Rodríguez-Cabello, P. Mela, Mater. Sci. Eng. C 2018, 88, 140.

[266] R. G. M. Breuls, T. U. Jiya, T. H. Smit, Open Orthop. J. 2008, 2 , 103.

[267] R. L. DiMarco, D. R. Hunt, R. E. Dewi, S. C. Heilshorn, Biomaterials 2017, 129, 152.

[268] H. Lv, L. Li, M. Sun, Y. Zhang, L. Chen, Y. Rong, Y. Li, Stem Cell Res. Ther. 2015, 6, 103.

[269] O. Chaudhuri, S. T. Koshy, C. Branco da Cunha, J.-W. Shin, C. S. Verbeke, K. H. Allison, D. J. Mooney, Nat. Mater. 2014, 13, 970.

[270] A. S. Mao, J.-W. Shin, D. J. Mooney, Biomaterials 2016, 98, 184.

[271] M. G. Haugh, T. J. Vaughan, C. M. Madl, R. M. Raftery, L. M. McNamara, F. J. O'Brien, S. C. Heilshorn, Biomaterials 2018, 171, 23.

[272] B. Trappmann, B. M. Baker, W. J. Polacheck, C. K. Choi, J. A. Burdick, C. S. Chen, Nat. Commun. 2017, 8, 371.

[273] T. Flora, I. González De Torre, M. Alonso, J. C. Rodríguez-Cabello, Biofabrication 2019, 11, 035008.

[274] C. M. Madl, L. M. Katz, S. C. Heilshorn, ACS Macro Lett. 2018, 7 , 1302.

[275] C. M. Madl, B. L. LeSavage, R. E. Dewi, C. B. Dinh, R. S. Stowers, M. Khariton, K. J. Lampe, D. Nguyen, O. Chaudhuri, A. Enejder, S. C. Heilshorn, Nat. Mater. 2017, 16, 1233.

[276] C. M. Madl, B. L. LeSavage, R. E. Dewi, K. J. Lampe, S. C. Heilshorn, Adv. Sci. 2019, 6, 1801716.

[277] K. S. Straley, S. C. Heilshorn, Adv. Mater. 2009, 21, 4148.

[278] J. Glowacki, S. Mizuno, Biopolymers 2008, 89, 338.

[279] E. Meco, K. J. Lampe, Biomacromolecules 2019, $20,1914$.

[280] K. E. Inostroza-Brito, E. Collin, O. Siton-Mendelson, K. H. Smith, A. Monge-Marcet, D. S. Ferreira, R. P. Rodríguez, M. Alonso, J. C. 
Rodríguez-Cabello, R. L. Reis, F. Sagués, L. Botto, R. Bitton, H. S. Azevedo, A. Mata, Nat. Chem. 2015, 7, 897.

[281] D. Mozhdehi, K. M. Luginbuhl, J. R. Simon, M. Dzuricky, R. Berger, H. S. Varol, F. C. Huang, K. L. Buehne, N. R. Mayne, I. Weitzhandler, M. Bonn, S. H. Parekh, A. Chilkoti, Nat. Chem. 2018, $10,496$.

[282] M. Weber, I. Gonzalez de Torre, R. Moreira, J. Frese, C. Oedekoven, M. Alonso, C. J. Rodriguez Cabello, S. Jockenhoevel, P. Mela, Tissue Eng. Part C Methods 2015, 21, 832.

[283] I. Gonzalez de Torre, M. Weber, L. Quintanilla, M. Alonso, S. Jockenhoevel, J. C. Rodríguez Cabello, P. Mela, Biomater. Sci. 2016, $4,1361$.

[284] B. Gurumurthy, J. A. Griggs, A. V. Janorkar, J. Mech. Behav. Biomed. Mater. 2018, 84, 116.

[285] S. S. Amruthwar, A. V. Janorkar, Dent. Mater. 2013, 29, 211.

[286] J. M. Caves, W. Cui, J. Wen, V. A. Kumar, C. A. Haller, E. L. Chaikof, Biomaterials 2011, 32, 5371.

[287] J. M. Caves, V. A. Kumar, A. W. Martinez, J. Kim, C. M. Ripberger, C. A. Haller, E. L. Chaikof, Biomaterials 2010, 31, 7175.

[288] B. Gurumurthy, P. C. Bierdeman, A. V. Janorkar, Dent. Mater. 2016, $32,1270$.

[289] J. S. Barbosa, A. Ribeiro, A. M. Testera, M. Alonso, F. J. Arias, J. C. Rodríguez-Cabello, J. F. Mano, Adv. Eng. Mater. 2010, 12, B37.

[290] I. L. Moss, L. Gordon, K. A. Woodhouse, C. M. Whyne, A. J. M. Yee, Spine (Phila. Pa. 1976). 2011, 36, 1022.

[291] D. Zhu, H. Wang, P. Trinh, S. C. Heilshorn, F. Yang, Biomaterials 2017, 127, 132.

[292] H. Wang, D. Zhu, A. Paul, L. Cai, A. Enejder, F. Yang, S. C. Heilshorn, Adv. Funct. Mater. 2017, 27, 1605609.

[293] E. Shirzaei Sani, R. Portillo-Lara, A. Spencer, W. Yu, B. M. Geilich, I. Noshadi, T. J. Webster, N. Annabi, ACS Biomater. Sci. Eng. 2018, $4,2528$.

[294] S. Ravi, J. M. Caves, A. W. Martinez, C. A. Haller, E. L. Chaikof, J. Biomed. Mater. Res. Part A 2013, 101A, 1915.

[295] H. Wang, L. Cai, A. Paul, A. Enejder, S. C. Heilshorn, Biomacromolecules 2014, 15, 3421. 
[296] L. Cai, R. E. Dewi, S. C. Heilshorn, Adv. Funct. Mater. 2015, 25, 1344.

[297] A. Fernández-Colino, F. Wolf, S. Rütten, T. Schmitz-Rode, J. C. Rodriguez-Cabello, S. Jockenhoevel, P. Mela, Front. Bioeng. Biotechnol. 2019, 7, 340. 